\author{
August 2014
}

\title{
REFORMING PUBLIC SERVICE PROVISION: WHAT HAVE WE LEARNED?
}

\author{
Peter Birch Sørensen \\ University of Copenhagen, EPRU and CESifo
}

Background paper for keynote lecture presented at the CESifo Venice Summer Institute Workshop on REFORMING THE PUBLIC SECTOR at Venice International University, 25-26 July 2014

\begin{abstract}
The essay discusses some key features of the wawe of public sector reforms that has swept through the OECD area during the last three decades under the heading of New Public Management. I review what economic theory and the empirical evidence can say about the effects of introducing pay for performance, performance measurement and various forms of competition in the public sector. I also review some evidence on the growing bureaucratization of the public sector and discuss the drivers behind this trend. The final part of the essay draws some implications for the design of public sector reforms.
\end{abstract}

Address for correspondence:

Peter Birch Sørensen

University of Copenhagen, Department of Economics

Øster Farimagsgade 5, 1353 Copenhagen K, Denmark.

E-mail: pbs@econ.ku.dk 


\title{
REFORMING PUBLIC SERVICE PROVISION: WHAT HAVE WE LEARNED?
}

\author{
Peter Birch Sørensen ${ }^{1}$ \\ University of Copenhagen, EPRU and CESifo
}

"It is quite true what philosophy says, that life must be understood backward. But then one forgets the other principle, that it must be lived forward." Søren Kierkegaard, Danish philosopher, 1813-1855.

\section{Setting the scene}

As Søren Kierkegaard told us, we humans are doomed to take actions without being able to foresee their consequences. This leads to many regrets, in public affairs as well as in personal life. In particular, when we experiment with reforming an organism as complex as the modern public sector, regrets are almost inevitable, and this paper will illustrate some examples.

Public sector reform has been high on the policy agenda in the OECD area for at least three decades now. In the early 1980s many OECD governments struggled with large budget deficits during the recession triggered by the second OPEC oil price shock. Following a long period of rapid public sector expansion, several countries embarked on a series of public sector reforms aimed at containing public expenditure and improving public sector productivity.

Today the situation is very similar. In the wake of the recent financial crisis and the European sovereign debt crisis, the advanced economies need to consolidate their public finances, and governments are seeking new ways of meeting the need for public services with fewer resources. In a longer run perspective, population ageing will also increase the pressure on public budgets and is already forcing governments to rethink many of their spending programs and practices.

Against this background I will discuss some important issues of public sector reform. To limit the scope of the analysis, I will not consider reforms of public transfer programs such as social insurance systems. ${ }^{2}$ Instead I will focus on reforms of public service provision.

\footnotetext{
${ }^{1}$ In preparing this paper I have drawn on my work as chairman of the Danish government's Productivity Commission in 2012-2014 and as a current member of the Norwegian government's Productivity Commission. I thank the members of these committees and their secretariats for inspiring discussions. I have also benefited from the studies prepared for the Danish Productivity Commission by Lotte Bøgh Andersen, Peter Bogetoft, Jørgen Grønnegaard Christensen, Niels Ejersbo, Carsten Greve, Anne Line Tenney Jordan, Kurt Houlberg and Jesper Wittrup. None of these persons or institutions are accountable for any viewpoints expressed in this paper or for any shortcomings of my analysis.

${ }^{2}$ I have done so elsewhere together with Lans Bovenberg and Martin Hansen. See, e.g., Bovenberg and Sørensen (2004) and Bovenberg, Hansen and Sørensen (2012).
} 
Only a few public services provided by the modern welfare state are genuine public goods such as defence, police protection, the court system and basic infrastructure. Most public services are private goods that are rival and excludable in consumption and could alternatively be purchased in the marketplace. James Tobin (1970) coined the term "specific egalitarianism" to explain why most western governments have nevertheless decided to offer these services to citizens free of charge or at user fees far below the costs of production. As Tobin argued, certain goods such as education and health care are so important for individual welfare that every citizen should be guaranteed a minimum level of consumption of these goods regardless of his or her ability to pay. In other words, it is the duty of the state to ensure that the unequal distribution of income does not generate a similar inequality in the consumption of certain vital goods. I take for granted that the welfare states in Europe and elsewhere wish to uphold the principle of specific egalitarianism and will therefore continue to provide several important services to citizens via the public budget. I will discuss what economic theory and evidence can say about the possibilities for delivering these services in a more efficient manner.

The social science literature on public administration and public sector reform is enormous, so my discussion has to be highly selective. I will focus on normative issues and will only sporadically discuss the political economy factors determining whether public sector reforms can actually be successfully implemented. ${ }^{3}$ I start in section 1 by motivating why public sector reform is so important. Section 2 reviews some peculiar features of the public sector that any reform strategy must take into account. In section 3 I sketch the main elements of the so-called New Public Management (NPM) that has provided the agenda for many public sector reforms in recent decades. Sections 4 through 6 discuss whether public sector efficiency can be improved through NPM mechanisms such as pay for performance, performance measurement, yardstick competition, vouchers and outsourcing of public service provision. In section $7 \mathrm{I}$ discuss the drivers behind "red tape" in the public sector. The concluding section 8 summarizes my main findings and discusses their implications for public sector reform. Two technical appendices document some of the theoretical results reported in the main text.

\section{A fundamental threat to the welfare state: Baumol's cost dis- ease}

One simple reason why an efficient public sector is important for prosperity and welfare is that so many people work there. As illustrated in figure 1, almost a third of the labour force works for the general government in countries like Norway and Denmark, and the average OECD government employed about 16 percent of the country's total work force

\footnotetext{
${ }^{3}$ For an overview of this important issue see, e.g., Høj et al. (2006) and Bunse and Fritz (2012).
} 
in 2011. In addition, almost 5 percent of the labour force worked in publicly owned corporations (OECD (2013, p. 102)).

Figure 1. Employment in general government as a percentage of the labour force

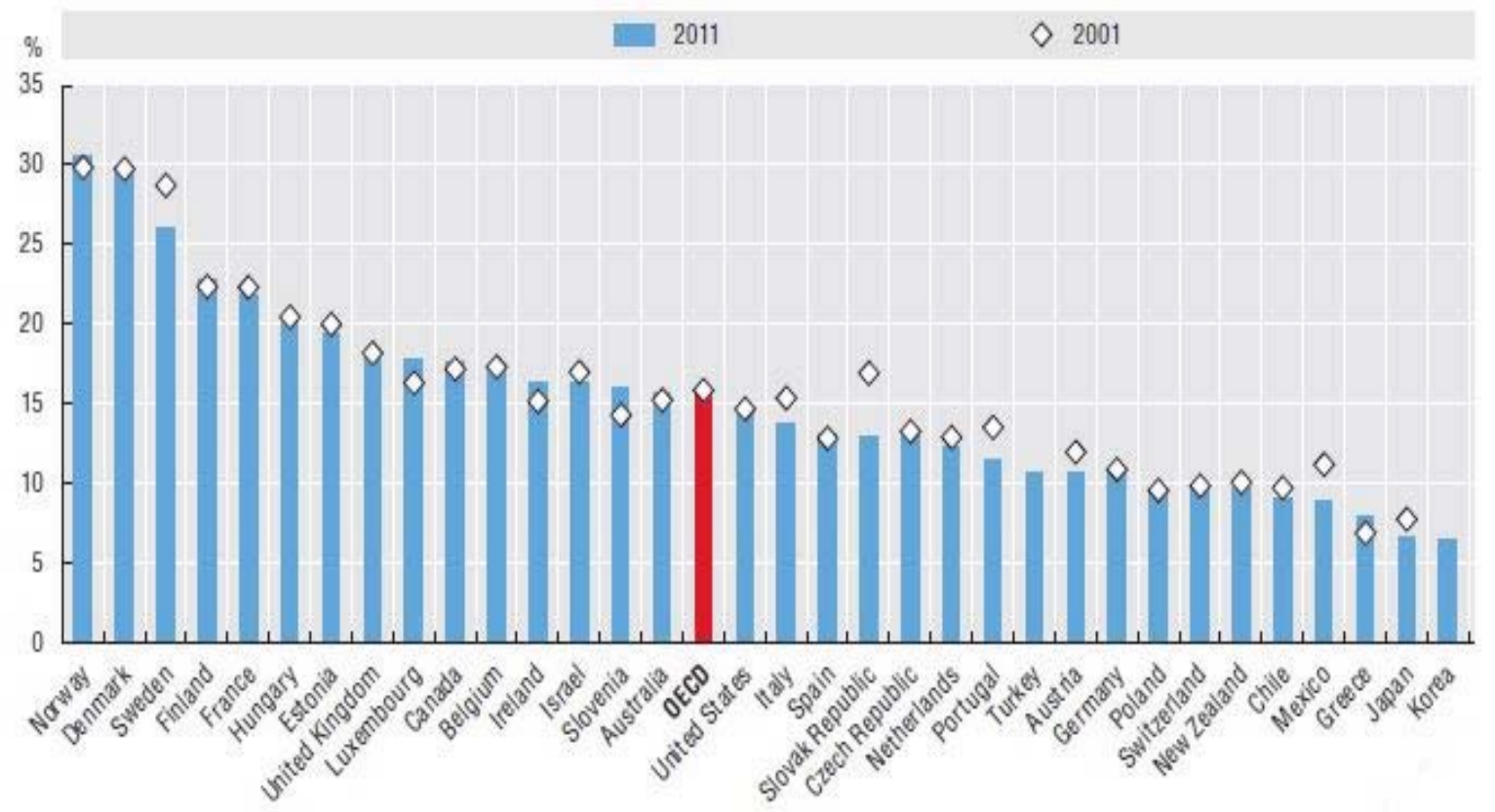

Note: The numbers do not include persons employed in public corporations.

Source: OECD (2013, figure 5.1).

Most public sector workers are engaged in labour-intensive service production. Many years ago William Baumol (1967) argued that, for technological reasons, it is impossible to raise productivity in this type of production as fast as productivity in many parts of the private sector such as manufacturing. But in order to attract workers, the public sector has to offer the same wage rates as the private sector. Private sector wages tend to increase in line with productivity, so if productivity grows faster in the private than in the public sector and both sectors must pay the same wage rates for the same types of labour, the relative cost of public services will increase over time. If the quantity of public services is allowed to increase in line with the quantity of private consumption, the overall tax burden as a share of GDP will therefore have to increase over time. During a large part of the 20th century this is what actually happened, but there is a limit to the amount of taxes voters are willing to pay. Baumol therefore anticipated that it would become increasingly hard to expand the (quality-adjusted) quantity of public services in line with real private consumption.

The essence of Baumol's story is that labour-intensive services - including those provided by the government - suffer from a "cost disease" that keeps on raising their relative 
prices, since productivity growth in these areas of production cannot keep pace with productivity growth elsewhere in the economy.

Productivity growth in many private service industries is hard to measure, because changes in service quality can be difficult to observe. Productivity growth in public service production is even harder to pin down, since these services are not traded in a marketplace where observed market prices provide an indicator of the value of output to consumers. However, the national income statistics of OECD countries do suggest a long run tendency for labour productivity to grow more slowly in most private service industries than in agriculture and manufacturing. In recent years the national statistical offices in EU member states have implemented a so-called output-based method of productivity measurement aimed at estimating the growth of labour productivity in the public sector. For what they are worth, these statistics also suggest that productivity growth in the public sector tends to lag behind the average productivity growth rate in the private sector. ${ }^{4}$

Such unbalanced productivity growth has some unpleasant implications for the future of tax-financed public services. This may be illustrated by some model simulations presented in a recent report by the Danish Productivity Commission (2014b, ch. 5). The simulations were carried out by the DREAM Modelling Group (2014), using a large scale dynamic overlapping generations model of the Danish economy. According to the Danish national income accounts, the average annual growth rate in real output per hour worked in the period 2001-2010 was roughly 1.5 percent in the private sector, whereas it was only about 0.5 percent in the public sector. In a baseline scenario it was assumed that these average productivity growth rates will be maintained in the future and that the ratio of total public consumption to GDP measured in current prices will be kept roughly constant. On these assumptions the DREAM model was used to project the underlying trend in real private consumption and in the real public service level. The latter variable was calculated as the ratio between the projected real public service output and the service output that would be needed to maintain the 2012-level of public service provision for each person of a given age, sex and ethnic background in each of the various public service areas such as education, child care, care for the elderly etc., given the expected demographic developments in Denmark. ${ }^{5}$

In figure 2 the overall public service level and real private consumption have both been normalized to 1.0 in 2012. The solid green curve shows the evolution of the public service level in the baseline scenario, and the black curve with the white circular dots

\footnotetext{
${ }^{4}$ One serious limitation of official national income statistics is that - because of limited data availability - they do not attempt to adjust for changes in the quality of public services. Another limitation is that the value of non-market public services has to be measured from the cost side, even though the cost of production does not necessarily reflect citizens' willingness to pay for the services.

${ }^{5}$ In the health care sector it was assumed that some of the health care services to the elderly will gradually be postponed to a higher age due to so-called "healthy aging".
} 
shows the path of private consumption which is projected to increase by almost 50 percent between 2012 and 2040, roughly in line with the growth of GDP. By contrast, we see that the public service level only increases by about 15 percent in the baseline scenario. The main driver of the latter increase is the assumed 0.5 percent annual increase in labour productivity, but since this is much lower than the 1.5 percent private sector productivity growth rate, and since public consumption in current prices is not allowed to increase relative to GDP, the public service level is projected to lag seriously behind real private consumption.

Figure 2. Projected private and public consumption in Denmark

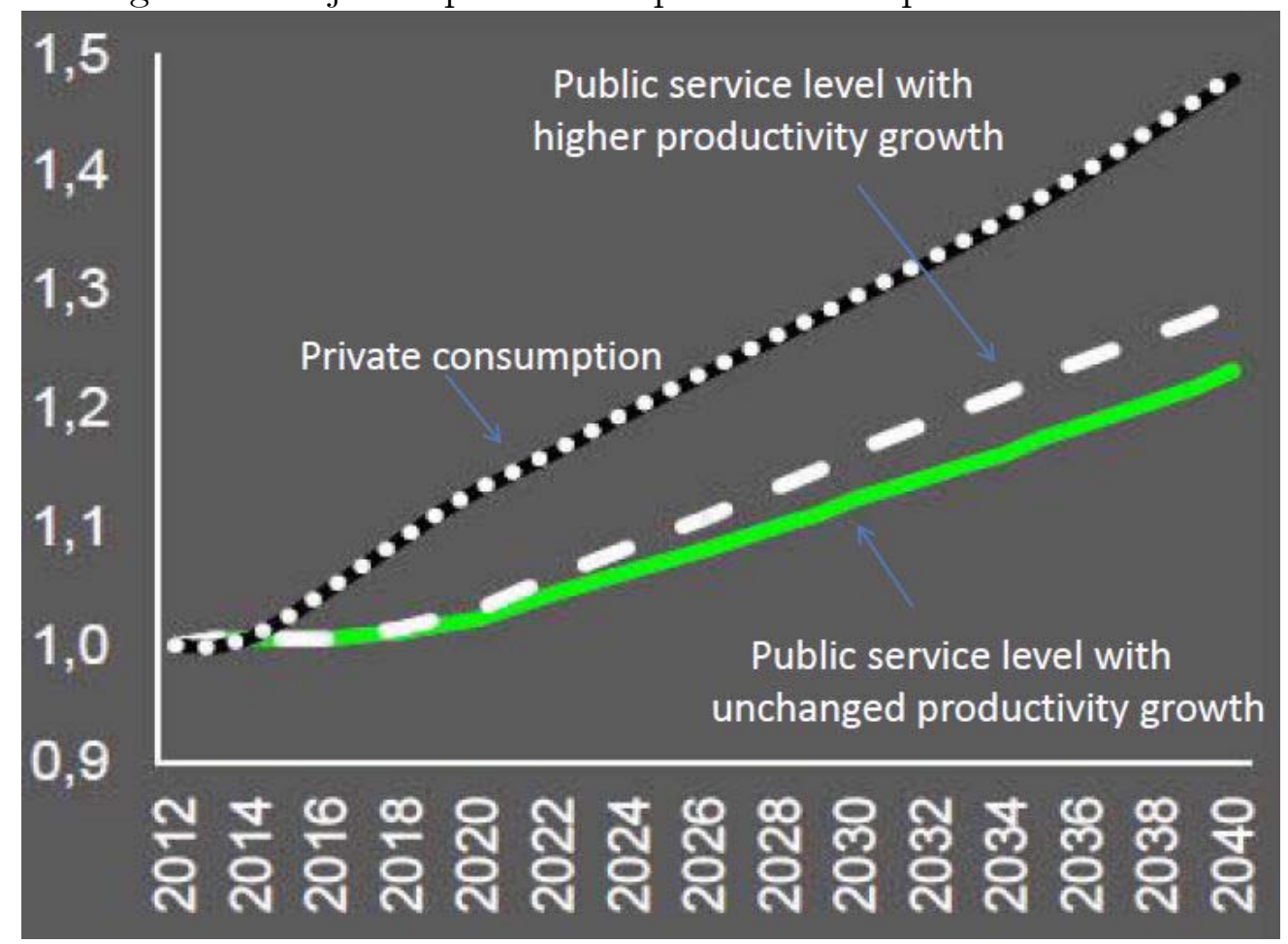

Note: The public service level is calculated as the ratio of actual real public consumption to the amount of public consumption that would be needed to keep public service provision per person in each demographic group constant. See the text for further explanation.

Source: Danish Productivity Commission (2014b, figure 30).

In an alternative scenario indicated by the white dotted line in figure 2 , it is assumed that labour productivity growth in the public sector is gradually doubled from 0.5 percent to 1 percent per year between 2012 and 2020. Between 2020 and 2030 annual public sector productivity growth is maintained at 1 percent, but is then assumed to fall back gradually to 0.5 percent in 2040 . We see that such a temporary doubling of public sector productivity growth will only close a small part of the projected rising gap between private and public consumption. 
These simulations highlight the powerful long run implications of Baumol's cost disease. While the income elasticity of demand for public services such as education and health care is often believed to be at least one, the actual consumption of such services will have to grow much slower than private consumption and GDP, unless voters are prepared to let the government tax away an ever-increasing share of their income. This underscores the importance of thinking about ways to increase public sector productivity to counter the growing mismatch between private living standards and public service provision.

\section{What is special about the public sector?}

The high labour-intensity of public service production is one important characteristic of the public sector. The sector also has some other special features that any reform strategy must take into account. Unfortunately several of these features tend to inhibit productivity growth. In this section I will discuss those features that seem most important from an economic perspective.

A basic observation is that, whereas private firms are owned by entrepreneurs or shareholders, public agencies are owned collectively by political communities and funded largely by taxation rather than fees paid directly by customers. Thus public sector organizations are controlled by political forces rather than market forces. This distinction leads to a number of hypotheses regarding the particular goals, structures and values of public sector organizations (see, e.g., Boyne (2002)). Some peculiarities that are often emphasized in the literature are listed below. ${ }^{6}$

\subsection{Special features of public sector organizations}

Little or no competitive pressure. Although the users of public services may sometimes choose freely among alternative providers, many public sector organizations are (local) monopoly suppliers of the service they produce, and their budgets are determined in a political or bureaucratic process. The absence of competition and the political constraint on total spending mean that the more efficient public sector organizations cannot grow at the expense of less efficient organizations. This contrasts with the private sector where the more efficient firms can conquer markets shares from the less efficient producers through the process of competition and creative destruction. Moreover, the lack of competition may stifle the incentive to keep costs low and to innovate.

Weak or distorted economic incentives. For a number of reasons elaborated in section 4 , the use of economic incentives such as performance bonuses and performance-based pay

\footnotetext{
${ }^{6}$ The list is far from complete, but it includes the features that seem most important to me. For an elaboration see, e.g., Rainey and Bozeman (2000) and Boyne (2002).
} 
schemes is less prevalent in the public than in the private sector. Hence the public sector must rely more on other forms of motivation and incentives to ensure good performance. In some cases the economic incentives in public sector organizations may even encourage waste. A standard example is a scenario where an agency engages in unnecessary spending towards the end of the fiscal year for fear that its budget for next year will otherwise be cut. A related problem is that a public agency may have no incentive to make investments that will reduce future costs if it expects that all of the cost saving will translate into a smaller future budget.

Multiple or ambiguous goals. A private firm may have several intermediate goals and groups of stakeholders, but in the end all other goals are irrelevant if the firm cannot make enough profit to survive and generate the minimum return required by its owners. Public sector organizations typically have many stakeholders such as the users of their services, their employees, the general public, and politicians of different persuasions, and they rarely have a single ultimate goal overriding all the others. Hence public agencies may often strive to achieve several and even conflicting goals, and it may not be clear what weight they are expected to put on the different objectives. Moreover, since the stated goals of public institutions may reflect political compromises, they may be deliberately vague due to a lack of political consensus. Such ambiguity poses a challenge to public sector managers and makes it difficult to determine whether public sector organizations perform well or badly.

Bureaucracy. A classic perception is that public sector organizations are more loaded with "red tape" than private firms. This may be unavoidable, since resource allocation in the public sector cannot be guided by market mechanisms, and since basic principles such as the rights of all citizens to receive equal treatment and the need to prevent corruption necessitate the use of various bureaucratic procedures. Of course, a private firm must also use command-and-control mechanisms to allocate resources within the organization, but the popular belief is that there is a stronger inherent tendency in the public sector to create excessive bureaucracy. In section $7 \mathrm{I}$ will discuss how such a tendency may arise. Here I just note that if the public sector does in fact generate a lot of unnecessary bureaucracy, productivity will obviously suffer.

Special values and preferences. It is often claimed that public sector managers and employees are less materialistic and more altruistic than their private sector counterparts. It is believed that public sector workers have a stronger motive to serve the public interest and do good for their customers/clients or for society at large, either because individuals with such motivation self-select into public sector employment; because the idealistic goals of public sector organizations tend to instil such values into the minds of their employees, or because people are more willing to behave altruistically when they work for a notfor-profit employer who cannot exploit their idealism. Another hypothesis is that public sector workers are on average more averse to risk than private sector workers, perhaps 
because people with stronger risk aversion prefer to work in the public sector where job security tends to be greater than in the private sector. Sometimes it is also claimed that individuals with a relatively high marginal disutility of work ("lazy" people) tend to select into public sector jobs because many of these jobs require less effort or shorter working hours than private sector employers demand.

A more regulated labour market. Trade union density tends to be greater in the public than in the private sector and centralized, collective bargaining over wages and work conditions seems to be more prevalent in the public sector. In addition, many countries have long traditions of offering certain groups of public employees a status as public servants (in German: "Beamter") with high job security and strong emphasis on pay schedules based on seniority. ${ }^{7}$ More generally, important conditions of work and pay are typically determined above the level of the individual public agency. Hence the individual public sector manager may have little freedom to fire underperforming employees or to differentiate the wage rates within the organization. Further, if trade unions are stronger or more prevalent in the public than in the private sector, the average wage level for a given type of workers may be higher in the public sector. At the same time the more centralized wage setting there may imply a lower degree of wage dispersion and a lower average wage for public than for private managers.

\subsection{Evidence on the differences between public and private sector organiza- tions}

Testing the above hypotheses on the difference between public and private organizations is not necessarily easy. For example, how do you measure the degree of bureaucracy, the degree of public service motivation and risk aversion, or the ambiguity of the goals of an organization? Most of the empirical research on these issues has relied on surveys and questionnaires where managers and workers are asked a number of questions about their practices, perceptions and attitudes. Sometimes such data on self-reported behaviour and preferences has been combined with hard data on observed behaviour and characteristics.

The proposition that public sector organizations are on average less subject to competitive (market) pressures than private firms seems obvious and has not really been disputed in the literature. Likewise, it is widely acknowledged that performance-based pay schemes and similar economic incentive mechanisms are less widespread in the public sector (this is also reflected in the data on wage dispersion presented below).

Most comparative studies of public and private sector organizations have tried to uncover differences regarding organizational goals, the degree of bureaucracy, and the preferences and values of managers and employees. In a meta-analysis Boyne (2002)

\footnotetext{
${ }^{7}$ In return for job security, some of these public servants may not have the right to strike, even if they are allowed to be members of a union.
} 
evaluates evidence from 34 empirical studies of differences between public agencies and private firms. $^{8}$ He finds that the balance of the evidence offers some support for the proposition that public agencies have more ambiguous goals. The evidence is not compelling, however, and in the United States the answers of public managers to survey questions about goal complexity and ambiguity do not seem to differ significantly from the answers given by business managers, as pointed out by Rainey and Bozeman (2000).

Among the studies that have compared the degree of bureaucracy, Boyne (2002) finds that a majority of them supports the hypothesis that there is more bureaucracy in public agencies. This contrasts with the literature review by Rainey and Bozeman (2000) who report that public managers do not differ from business managers in response to survey questions about the degree of formalization and red tape within their organizations. Perhaps this ambiguity of findings reflects the difficulty of defining and measuring such a thing as "red tape".

The review by Boyne (2002) reveals considerable empirical support for the hypothesis that public managers are less materialistic in the sense of being less motivated by monetary rewards than private business managers. Quite a few studies have also tried to identify differences in preferences between public and private sector workers below the management level. Most of these studies find that, on average, public sector employees do indeed seem to have a stronger public service motivation (wishing to do good for others or for society at large) than private sector employees. For example, the study by Jakobsen and Sørensen (2012), using survey data for 13 countries for 1989, 1997 and 2005, finds a significant and stable difference in the degree of public service motivation between the two sectors.

One weakness of survey data is that they reflect self-reported behaviour or preferences which may deviate from actual behaviour and preferences. Buurman et al. (2012) avoid this problem by using experimental data on revealed rather than stated preferences to study whether public sector employees are more altruistic and risk averse than people employed in the private sector. Respondents to a large-scale survey were offered a substantial financial reward and could choose between a widely redeemable gift certificate, a lottery ticket, or making a donation to a charity. The authors found that public sector employees were significantly less likely to choose the risky option (lottery). This is consistent with the hypothesis that public employees tend to be more risk averse. Buurman et al. (2012) also found that, at the start of their career, public sector workers were more likely to choose the pro-social option (charity). However, as job tenure increased, the difference in pro-social behaviour disappeared and was even reversed at some point. The authors explained this reversal by a gradual disillusionment effect reflecting that public sector workers with long tenures feel that they already contribute enough to society for

\footnotetext{
${ }^{8}$ Only a subset of these studies has tested all of the hypotheses regarding organizational goals, bureaucracy and values and preferences.
} 
too little pay.

An interesting issue is whether the stronger public service motivation of public workers reflects the institutional environment or whether it results from self-selection of idealistic people into the public sector. Gregg et al. (2011) try to resolve this issue by exploiting data on unpaid overtime work from the British Household Panel Survey. They show that individuals in the economy's non-profit sector (which includes the general government) are significantly more likely to do unpaid overtime than those in the for-profit sector, in line with the hypothesis that public workers display more pro-social behaviour. However, when individuals who are willing to "donate" labour move from the non-profit to the for-profit sector, they seem no less willing to do unpaid overtime work. This suggests that the stronger inclination towards pro-social behaviour in the public sector reflects a self-selection effect rather than an effect of the institutional environment.

Another interesting issue is whether such a selection effect simply reflects that people with a pro-social motivation select into specific occupations such as nursing, (nursery) teaching, medicine, and other occupations within the classical welfare services that are predominant in the public sector. Andersen and Pedersen (2013) use Danish survey data to test for significant differences in motivation between private and public sector employees within a given occupation. According to their study, employees in publicly owned organizations more frequently report that is is important to contribute to the community and that it is a civic duty to deliver public service. However, employees in private organizations are found to have higher levels of user orientation, reporting more frequently that it motivates them to know that they helped the user, that the job is done when the user is satisfied, and that the individual user is more important than formal rules. Thus both private and public sector employees may be said to harbour prosocial preferences, but in the public sector these preferences are more oriented towards serving the general public whereas they are more geared towards serving the individual client/customer in the private sector.

As mentioned in the previous section, some people have claimed that the public sector tends to attract more "lazy" workers, because public sector employers do not always require as much effort (or as long working hours) from their employees as do private employers. If this claim is true, we should expect to see "lazy" workers moving more frequently from private to public sector jobs than moving in the opposite direction. But how do we determine whether a worker is "lazy"? Delfgaauw and Dur (2008) use U.S. and Dutch survey data when trying to answer this question. In their U.S. data set the indicator of laziness is the response to the statement: 'I see myself as someone who is lazy at times.' In the Dutch survey data the degree of laziness is measured by the answer to the question whether a preference for reduced work load was one of the three most important reasons for leaving the previous job. Using these indicators, Delfgaauw and Dur found that "lazy" workers in both countries do in fact tend to move from private to 
public sector jobs more frequently than they move in the opposite direction. The issue of course is whether this really reflects that public sector workers are inherently more lazy in the sense of having a higher marginal disutility of work for any given amount of effort, or whether it reflects that some people working in the public sector have to spend more time on (family) duties at home or choose to invest some of their working time outside the formal labour market (e.g. doing voluntary work).

While testing for differences in preferences across private and public sector workers is hard, due to the difficulty of observing preferences, it is easier to document the differences between private and public sector labour markets. Using data for 14 OECD countries, including the Anglo-Saxon countries and France, Germany and Spain, among others, Visser (2006, table 4) shows that trade union densities are generally much higher in the public than in the private sector. This is in line with the findings of Gregory and Borland (1999) who also point out the following main facts: (i) Public sector employment tends to be concentrated in professional and clerical jobs and to require workers with relatively high levels of education. (ii) Public sector employees are generally found to have higher average earnings than private sector employees, in part reflecting higher levels of educational attainment, and partly reflecting (in most countries) a genuine wage premium that could be due to a higher degree of unionization. (iii) Public sector employees have a more compressed distribution of earnings than private sector employees.

The latter fact is illustrated in figure 3 which shows the wage distribution for public and private sector clerical workers in Denmark. The picture is the same for other occupational groups in Denmark: the wage distribution is much more narrow in the public than in the private sector. The Danish Productivity Commission (2013, table 8) also documents that only 8 percent of the Danish public sector wage bill is subject to local wage negotiations at the level of the individual work place; the remaining 92 percent of the wage bill is settled through centralized collective bargaining. This is in sharp contrast to the Danish private labour market where only 14 percent of the wage bill is determined through centralized bargaining, the remaining part being negotiated at the firm level.

As a general rule, management decisions on personnel also seem to be significantly more constrained in the public sector. For example, in the United States a large number of surveys have revealed sharp differences between the responses of public and private managers to questions about constraints under personnel rules. A high percentage of public managers say that they do not have enough authority to remove, hire, promote and determine the pay of their employees (Rainey and Bozeman, 2000, p. 455). 
Figure 3. Wage distribution for clerical workers in Denmark, 2010.

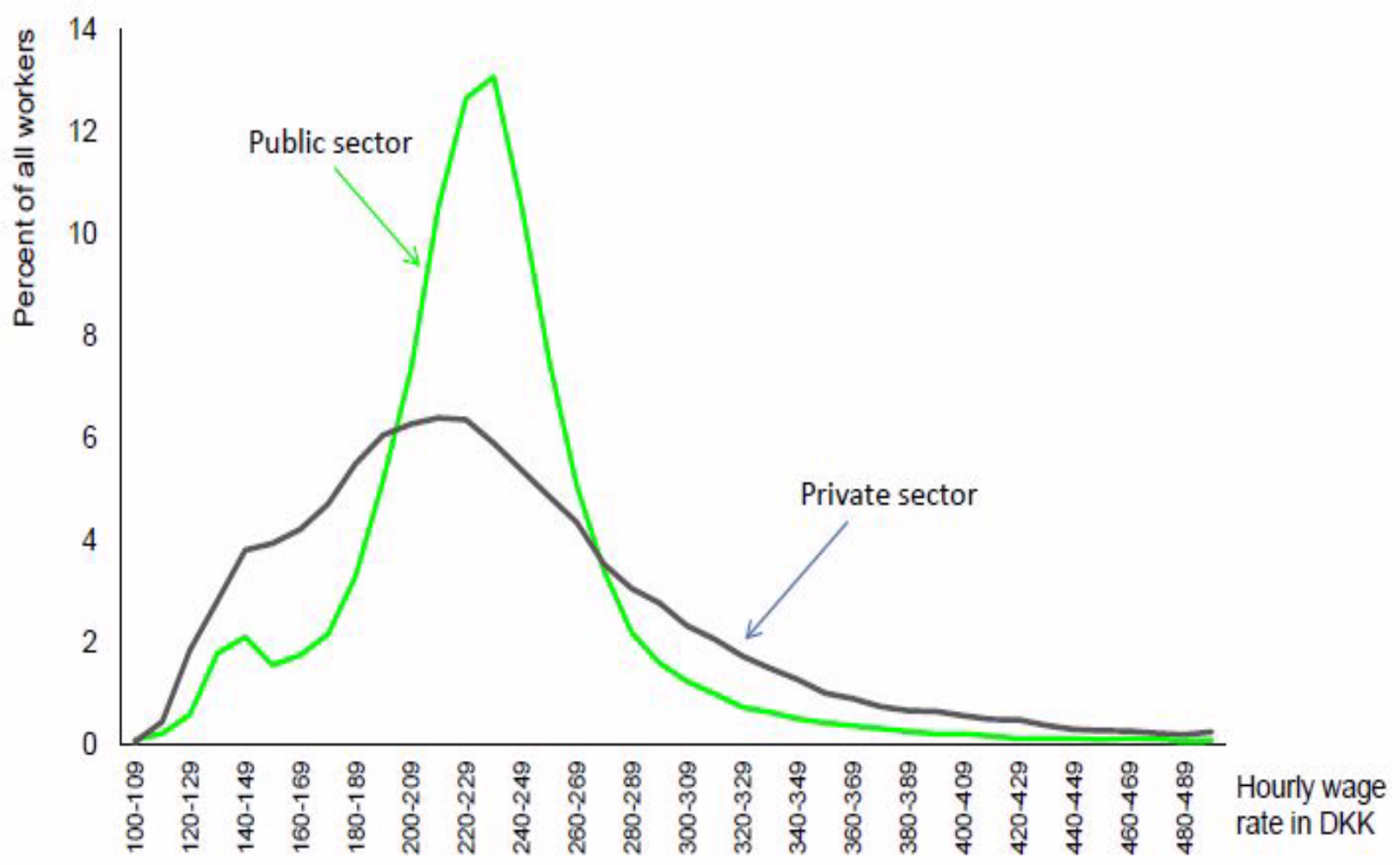

Source: Danish Productivity Commission (2013), based on data from Statistics Denmark.

This brief review of some key differences between the private and the public sector may be summarized as follows: Public sector organizations are generally less subject to competitive (market) pressure. They also face fewer high-powered economic incentives and sometimes none at all, and there is some evidence that public sector organizations have more bureaucratic procedures than private firms, perhaps for good reasons. Surprisingly, the evidence that public agencies have more complex and ambiguous goals seems relatively weak. By contrast, there is quite a lot of evidence suggesting that public sector employees are on average more motivated to serve society, reflecting that people with a strong public service motivation self-select into public sector employment. Likewise, the hypothesis that public sector workers are more risk averse than their private sector colleagues has found some empirical support. Finally, there is solid evidence that trade unions are stronger in the public sector, that the wage distribution is more compressed in that sector, and that public managers are more constrained in their personnel decisions than business managers. 


\section{A conventional reform agenda: From Old Public Administra- tion to New Public Management}

During the 1980s and 1990s a wave of public sector reforms swept through the OECD area and beyond, often under slogans such as "modernization", "debureaucratization" and "reinventing government". In several cases the reforms were triggered by fiscal crises, but they also reflected a growing dissatisfaction with the performance of existing government structures and a shift in the prevailing political and ideological mood in favour of more market-oriented policies. At least within the OECD, the reforms had many common features, following (albeit with different degrees of rigour) a paradigm which became known as the New Public Management (NPM). In this section I will sketch the main elements of NPM and briefly review the controversy that this reform agenda has created.

\subsection{Key features of New Public Management}

Proponents of NPM sought to escape from the principles of the so-called Old Public Administration characterized by centralized and hierarchical administrative structures and an emphasis on rules-based behaviour and fixed, impersonal bureaucratic procedures. NPM is not a tightly knit set of principles and policies. Its main ideas have evolved over time, and different authors have stressed different aspects of the paradigm (see, e.g., Hood (1989), Barzelay (2000) and Gruening (2001)). Both practitioners and academics have contributed to the development of the ideas underlying NPM. Some of these ideas were clearly stimulated by developments within the science of economics such as the emergence of principal-agent theory, and some reflected an attempt to transfer methods of private business management to the public sector. Inspired by Dunleavy et al. (2005), we may summarize some important features of NPM under the following headings.

Decentralization: Many NPM reforms involved a splitting up of large centralized and hierarchical administrative units into a number of smaller public agencies with more specialized tasks, separated by arms-length distance to the relevant central ministries. As part of this process, a clear distinction was introduced between the purchaser of some public service (e.g., a central ministry) and the provider of that service which could be a specialized government agency or a private firm. Instead of management by direct orders from the central administrative unit, the relationship between purchasers and providers typically came to be governed by some form of contract specifying the services and performance expected from the decentralized units. An important idea was that the managers of the decentralized units should be given more flexibility to solve their assigned tasks. "Let managers manage" became a slogan, and there was talk of a "big bargain" in which local managers would be freed from a lot of the centrally imposed regulation of work processes in return for greater accountability for the final results 
produced by their organizations. As Robert D. Behn has put it: 'Under the New Public Management, civil servants are not automatons, merely implementing policies according to rules promulgated from above. Rather, the public management paradigm assumes that civil servants are intelligent, that they understand the problems their agencies are charged with alleviating, that they have some useful ideas, either their own ones or borrowed from others, about how to fix those problems, and that they can, given the freedom, quickly convert those ideas into effective action. Indeed, the public management paradigm assumes that, because front line civil servants are close to the problems, they are in a very good position (perhaps the best position) to decide what approach to take in solving public problems.' (Behn, 1998, p. 133).

Incentivization: NPM reforms have often also sought to introduce stronger economic incentives for good performance in public sector organizations. For example, the performance contracts governing the relationships between purchasers and providers typically involved some kind of performance-related pay or bonus to local managers, and sometimes performance-based pay was also introduced for the employees at lower levels. Other important ways of strengthening economic incentives were the privatization of many formerly state-owned enterprises and the deregulation of various network industries previously under tight government control. Along with the introduction of performancerelated incentives followed the need for a more systematic measurement of performance, so efforts were made (at least in theory) to secure improved performance measurement and auditing on a systematic recurrent basis. The emphasis on decentralization and incentivization also created a need for improved methods of accounting and financial management within government agencies, and some countries introduced principles of accruals accounting and more sophisticated methods of cost allocation in their public sectors.

Competition: The introduction of various forms of competition in the public sector as an incentive to strengthen performance was an important element in many NPM reforms. Often this took the form of outsourcing the provision of public services via a process of competitive public tender. Although this frequently meant that a private firm took over the provision of the service, the incumbent public in-house provider was sometimes also allowed to bid for the task. Some countries and local governments also started experiments with various voucher schemes, allowing citizens to choose between alternative providers of a specific public service, thus empowering citizens to "vote with their feet" if they were unhappy with the performance of a particular provider. In cases where outsourcing or vouchers were thought to be impractical, governments often sought to introduce some form of "yardstick competition" as an integral part of performance measurement by requiring or encouraging individual public sector organizations to benchmark their performance against that of comparable units. 


\subsection{Experience with and critique of New Public Management}

The brief description above is a stylized account of NPM as it was supposed to work. In practice different countries emphazised different aspects of NPM in their specific reform efforts, and not all reforming countries have been equally zealous in adhering to the principles laid out above. In general, NPM was adopted most broadly and vigorously in the Anglo-Saxon countries, often with New Zealand and Australia as front-runners, whereas the continental European countries have been more hesitant and selective in drawing from the NPM toolbox (see Pollitt et al. (2007)).

Over the years the attempts to introduce elements of NPM have created heated controversies within the communities of scholars, civil servants, politicians and the general public. Sometimes the debate has degenerated into cultural and ideological warfare. ${ }^{9}$ Yet, although views on the merits or demerits of NPM still differ quite a lot, there is a growing acknowledgment that many of the NPM-inspired reforms have not in practice lived up to the orginal hopes and expectations. In the OECD, long inclined to advocate NPM, two officials wrote in 2003 that it had become evident that the public sector reforms of the two previous decades had generated some unforeseen negative and even perverse results (Matheson and Kwon (2003, p. 10)). ${ }^{10}$

In the eyes of some observers, this experiencee mainly reflected that the reforms often failed to implement NPM principles in the way originally conceived. For example, Behn (2002, p. 7) writes: 'If you ask public managers if they are using the various techniques of performance management, they will, of course, answer "yes". But if you examine what they are really doing, you will discover that they are not truly employing the principles in a manner that is apt to produce real improvements in outcomes and value. Performance management has not swept the world; it lives more in rhetoric than reality.' In particular, it seems that politicians and top executives failed to honour their "big bargain" promise of giving the decentralized executive bodies more flexibility to solve their tasks in return for more accountability for the final outcomes. Several observers in countries like the United States and United Kingdom noted that process controls over decentralized agencies were in many cases retained and augmented and that increased formality and regulation were imposed on them during the period when NPM reforms were carried out (Hood and Peters, 2004, p. 271). In short, it seems that the increased efforts to measure performance often resulted in more paperwork and bureaucracy.

\footnotetext{
${ }^{9}$ Reflecting such an atmosphere, the title of the article by Lapsley (2009) reads: 'New Public Management: The Cruellest Invention of the Human Spirit?' However, the discussion by the author himself is quite balanced.

${ }^{10}$ In Denmark, a group of former civil servants from the Ministry of Finance created quite a stir in 2007 when they published a newspaper article denouncing their earlier promotion of performance contracts and performance management. Their feature article carried the headline: 'Please forgive us - We didn't know what we were doing.' One is reminded of the quote from Søren Kierkegaard at the beginning of this essay.
} 
Many other observers (e.g., Savoie, 1995) have argued that NPM reforms were doomed to fail from the outset because they were based on much too narrow views of how the public sector works (and should work) and how its employees are motivated. Below I briefly mention some of the most frequent points of criticism against NPM.

Fragmentation: The splitting up of large public sector hierarchies into many smaller and more autonomous units with specialized tasks has been criticized for creating coordination problems within the public sector and for making it more difficult for the central government to steer the public sector in a desired direction in response to new societal needs. This critique, which will not be elaborated further in this paper, has led to the so-called Whole-of-Government Approach to public sector reform which stresses the need for greater horizontal and vertical collaboration and coordination between the different parts of the public sector (see, e.g., Christensen and Lægreid, 2007).

Naive belief in the scope for performance measurement: Critics of NPM often stress that the goals of many important public sector organizations are multidimensional and that the fulfilment of many of them (e.g., the goal of nurturing the social skills of school children) is hard to measure in quantitative terms. Thus a balanced performance measurement must often rely on qualitative judgements, so performance auditing and benchmarking based on quantitative indicators that are more easily measured runs the risk of distorting the incentives of public sector organizations, inducing them to put too much emphasis on the measured activities.

Increased bureaucracy and poorer working conditions as a result of outsourcing: Some critics point out that the alleged efficiency gains from outsourcing of public services are dubious, in part because private providers usually have a higher cost of capital than the government, and partly because of the transactions costs involved in organizing competitive public tenders, writing contracts with providers, and monitoring their performance. As a corollary, it is argued that the apparent cost savings from outsourcing often arise from a deterioration of the wages and working conditions of employees following the transition from public to private sector employment.

Clash with professional and civil service norms: This is perhaps the most fundamental criticism against NPM. The argument here is that economic incentives such as pay for performance and various forms of competition in the public sector tend to promote materialistic and self-interested behaviour at the expense of altruistic and public-service minded behaviour. This is the problem of extrinsic motivation potentially crowding out intrinsic motivation (see, e.g., Frey (1997)). There is a link here to the problem of performance measurement: if the incentive schemes only reward those activities and outcomes that are measurable, the result may be disillusionment among those employees who perform other important tasks which cannot be measured.

Because of these perceived shortcomings, the NPM paradigm has been proclaimed to be "dead" (Dunleavy et al. (2005)). However, even though OECD governments have 
begun to stress other objectives in recent public sector reforms,${ }^{11}$ many elements of NPM have remained in place in one way or the other, and components from the NPM toolbox continue to pop up in new reform proposals here and there. For these reasons, I will now discuss in more detail what we know and do not know about the usefulness of some of the most prominent features of NPM: pay for performance, performance measurement, and the introduction of competition in the public sector through vouchers and outsourcing. Following that, I will offer some reflections on the drivers behind excessive bureaucracy. ${ }^{12}$

\section{Pay for performance: does it work in the public sector?}

\subsection{An early experiment in New Public Management}

Critics of NPM argue that incentive schemes like pay for performance will not work in the public sector, either because the most important aspects of performance cannot be measured properly, or because public employees will not react to material incentives in the way expected. A mainstream economist would say that, if you pay a person to do more of some activity, you can normally expect that person to actually carry out more of that activity. Probably our economist would also say that, even though some of the outputs produced by public sector employees are hard to measure, other important outputs can in fact be measured, so that would leave at least some scope for the use of performance-related pay in the public sector.

An interesting historical example provides some encouragement for our mainstream economist. ${ }^{13}$ The English civil servant Edwin Chadwick (1800-1890) once suggested an improvement of the regulation of the transportation of British convicts to Australia. Originally the captains of the vessels commissioned for the transport were paid a flat fee per prisoner taken on board in the port of departure. At Chadwick's suggestion, the pay scheme was changed so that the captains were instead paid per prisoner who disembarked alive in Australia. Following this, the survival rate among the criminals increased from 40 percent to 98.5 percent! So at least this early experiment in New Public Management must be deemed a success.

Yet in section 2.2 we noted that pay for performance is not very frequently used in the public sector, at least not below the management level. The question is whether there are good reasons for this from the perspective of economic science? I will start by discussing what basic principal-agent theory - which assumes that people are self-interested - can

\footnotetext{
${ }^{11}$ See Greve (2013) for a review of some important recent ideas and trends in public sector reforms.

${ }^{12}$ To limit the scope of the paper I will not discuss the experience with privatization of state-owned enterprises. Megginson and Netter (2001) review the empirical evidence on this issue.

${ }^{13}$ The example is given by Sandmo (2014) who in turn draws on the account of Ekelund and Hébert (1997).
} 
teach us about this issue. I will then discuss how the answer might change once we allow for pro-social behavour of one kind or another.

\subsection{The scope for pay for performance: what can we learn from principal- agent theory?}

The idea that you cannot rely on trust alone when organizing public affairs is not an invention of economists. For example, in 1887 the later U.S. president Woodrow Wilson wrote: 'All sovereigns are suspicious of their servants, and the sovereign people is no exception to the rule' (Wilson, 1887, p. 20). And Vladimir Lenin is famously supposed to have said: 'Trust is good, but control is better.'

Principal-agent theory analyzes the optimal design of incentive schemes for an "agent" such as a worker when a "principal" such as a manager wants the agent to carry out some task that he does not necessarily want to do, and when the principal cannot fully observe and control the agent's behaviour. We can use insights from this theory to evaluate the scope for pay for performance in the public sector. ${ }^{14}$

\section{The basic principal-agent model with moral hazard}

Consider first a situation with one principal (say, a public manager) and one agent (say, a representative public service worker). The agent exerts effort $e$ which results in a stochastic outcome $x$ given by

$$
x=e+\varepsilon,
$$

where $\varepsilon$ is a random variable with zero mean and constant variance. This variable reflects that the outcome in which the principal is interested (say, how much school children learn) is subject to some influences beyond the control of the agent (e.g., the socioeconomic bacground of the pupils). The agent gets utility from his net payoff $y-C$, where $y$ is the agent's income, and $C$ is his cost of effort given by

$$
C=\frac{c e^{2}}{2}, \quad c>0, \quad c \text { constant. }
$$

According to (2) the agent's marginal cost of effort is $c e$, so the parameter $c$ measures the steepness of the rise in marginal cost as effort increases.

The principal can observe the outcome of the agent's effort and make his pay depend on it. For reasons of simplicity and transparency, the principal is constrained to use a linear pay scheme. Thus the agent is paid according to the following linear reward

\footnotetext{
${ }^{14}$ The exposition in the rest of this subsection is heavily inspired by Dixit (2002) but the results presented in eqs. (9) and (13) below are new, and my formulas (16) and (19) extend the related formulas in Dixit's paper by allowing for risk aversion on the part of the principal. Both Dixit and I draw on the more fundamental contributions by Holmström (1979, 1982) and Holmström and Milgrom (1991).
} 
schedule, where $k$ and $m$ are parameters chosen by the principal:

$$
y=k+m x .
$$

As shown in appendix A, an agent maximizing his expected utility will exert effort up to the point where

$$
e=\frac{m}{c}
$$

Not surprisingly, we see that the principal can call forth more effort from the agent by offering a higher marginal reward $(m)$ for additional output. ${ }^{15}$

The principal's realized utility depends on his net payoff $x-y$. The principal chooses $k$ and $m$ so as to maximize his expected utility, subject to the constraint that he must offer the agent an expected utility level at least as high as the expected utility the agent could attain in the best available alternative employment opportunity. Suppose now that the random variable $\varepsilon$ in (1) follows a normal distribution with variance $\sigma^{2}$ and that the principal and the agent both have constant absolute risk aversion. The principal's coefficient of risk aversion is $R(>0)$, while the agent has a coefficient of risk aversion $\rho$ $(>0)$. In these circumstances, appendix A shows that the value of the pay parameter $m$ which will maximize the principal's expected utility is

$$
m=\frac{1+c R \sigma^{2}}{1+c(\rho+R) \sigma^{2}} .
$$

This result, also reported in Dixit (2002, p. 699), shows that when both parties are risk averse, they should share the risk stemming from stochastic fluctuations in output, that is, $m$ should fall between zero and one. This means that the agent's pay should also depend on his output to some extent. According to (5), the agent's pay should be more strongly related to his performance ( $m$ should be higher) the higher the value of $R$, but less strongly related to performance the higher the values of $\rho$ and $\sigma^{2}{ }^{16}$ These results are intuitive: the stronger the principal's degree of risk aversion $(R)$, the more he will want to strengthen the agent's incentive to work hard to reduce the risk of a very bad outcome. On the other hand, the more risk averse the agent is, the more he will dislike the uncertainty arising when part of his income depends on an outcome he cannot fully control. Hence the principal will have to offer the agent a higher average pay (through a higher $k$ ) to compensate him for the income risk associated with any given value of $m$. When $\rho$ is higher, it therefore becomes optimal for the principal to choose a lower value of $m$ - and thereby impose less risk on the agent - to reduce the average wage cost. Similarly, when the variance of output is larger, the agent carries more risk for any given value of $m$ and must therefore be offered a higher average compensation, so again it becomes optimal for the principal to lower $m$.

\footnotetext{
${ }^{15}$ In this section I use the words "output" and "outcome" synonymously. In the next main section I will introduce a distinction between these two concepts.

${ }^{16}$ As the reader may verify from $(5), \partial m / \partial R>0, \partial m / \partial \rho<0$ and $\partial m / \partial \sigma^{2}<0$.
} 
This simple model suggests two reasons why it may be optimal to rely less on pay for performance in the public than in the private sector. As mentioned in section 3.2, there is some evidence that public sector workers are on average more risk averse than workers in the private sector. If $\rho$ is indeed relatively high in the public sector, eq. (5) implies that public sector wages should be less dependent on observed outputs. Second, it has been argued that many services in the public education and health care sectors are quite complex and that the final outcomes to which these sectors contribute (learning, social skills, health conditions, etc.) depend on a lot of factors beyond the control of the individual service worker. In the context of our model, this would mean that the variance $\sigma^{2}$ is relatively high in the public sector. As we have seen, this also calls for a relatively low value of $m$, ceteris paribus.

On the other hand, eq. (5) also suggests one reason why the public sector might actually want to rely more on performance-related pay. Specifically, the owners of private firms often have opportunities to diversify their risks. Hence principals in the private sector (owners and their appointed managers) may not worry so much as public principals about the risk associated with the activities of invididual production units. Indeed, since many of the services produced by public sector organizations are quite important for the welfare of citizens, and given the tendency of the media and the general public to focus on examples of bad performance in public agencies, the degree of risk aversion of public sector principals may well be relatively high. As Robert Behn has claimed: 'Indeed, in government, it does not matter if you get it right 99 percent of the time because the focus will be on the one percent of the time you get it wrong. That is why The Ten Commandments of Government are: Thou shalt not make a mistake. Thou shalt not make a mistake....Thou shalt not make a mistake' (Behn, 1998, p. 149). If public principals are in fact relatively risk averse, implying a high value of $R$, it follows from (5) that they should give their employees strong incentives to work hard (through a high value of $m$ ) to reduce the risk of very bad outcomes.

In summary, it is not quite clear from this basic principal-agent model with moral hazard - where agents have an incentive to shirk unless they are sufficiently rewarded for not doing so - that public sector organizations should rely less on performance-related pay than private firms. We will now consider some situations where the case for using low-powered incentives in the public sector becomes more clear-cut.

\section{Multiple agents}

Let us abstract for a moment from stochastic influences on output, and let us assume that there are two agents, 1 and 2 , whose efforts $e_{1}$ and $e_{2}$ contribute equally to total service output:

$$
x=e_{1}+e_{2} .
$$

Total output is still fully observable, but each agent's contribution to it can only be 
measured with a stochastic, symmetric normally distributed error, $\varepsilon$, with zero mean and constant variance $\sigma^{2}$. Hence the measured outputs of the two agents (indicated by hat superscripts) are

$$
\widehat{e}_{1}=e_{1}+\varepsilon, \quad \widehat{e}_{2}=e_{2}-\varepsilon .
$$

The individual agent is paid according to his measured performance, so the income of agent $i\left(y_{i}\right)$ is

$$
y_{i}=k+m \widehat{e}_{i}, \quad i=1,2 .
$$

Agent $i$ obtains utility from his payoff $y_{i}-C_{i}$. For both agents the cost of effort $\left(C_{i}\right)$ is given by (2), so they will both choose the level of effort reported in (4). Both of them also have the same degree of constant absolute risk aversion, $\rho$, and they must be offered a minimum level of expected utility equal to their best outside option (assumed to be the same for both agents).

The principal's payoff now becomes $x-y_{1}-y_{2}$. With these assumptions, appendix A shows that a utility-maximizing principal will offer the following marginal reward for measured effort:

$$
m=\frac{1}{1+c \rho \sigma^{2}} .
$$

We see that the principal's degree of risk aversion is now immaterial for the optimal pay scheme. The reason is that the principal's payoff is no longer stochastic, since eqs. (6) through (8) imply that total output as well as the total pay bill $y_{1}+y_{2}$ are both deterministic functions of $e_{1}$ and $e_{2}$ which are themselves non-stochastic according to (4).

Not surprisingly, eq. (9) also shows that, the greater the difficulty of measuring the individual agent's contribution to total output, i.e., the larger the variance $\sigma^{2}$, the weaker is the rationale for tying an agent's income to his measured output. So if it is indeed relatively hard to measure individual contributions to total service output, due to a high degree of complexity of public service production, the case for performance-related pay in the public sector is weakened.

Finally, eq. (9) confirms our earlier result that a relatively high degree of risk aversion among public sector workers likewise makes pay for performance less attractive.

\section{Teamwork with a collective bonus scheme}

Consider next a situation with a team of $n$ agents whose efforts contribute equally to an output which is subject to a stochastic influence, $\varepsilon$. Thus total output is

$$
x=\sum_{i=1}^{n} e_{i}+\varepsilon .
$$

Total output is still fully observable by the principal, but now he cannot pay the individual agent according to the latter's contribution to total output, either because the individual 
contribution is unobservable, or because an egalitarian norm dictates that all agents be paid the same wage. ${ }^{17}$ Instead, the principal pays each agent a wage consisting of a fixed component plus a bonus which is proportional to the average output per team member $(x / n)$ :

$$
y_{i}=y=k+m \frac{x}{n} .
$$

Maintaining the same assumptions on preferences and effort costs as before, appendix A demonstrates that the principal's optimal choice of the performance pay parameter now becomes

$$
m=\frac{1+c R \sigma^{2}}{\frac{1}{n}+c\left(\frac{\rho}{n}+R\right) \sigma^{2}} .
$$

Eqs. (10) through (12) imply that the reward for the individual worker's marginal contribution to total output $\left(m_{i}=\frac{m}{n}\right)$ becomes

$$
m_{i}=\frac{1+c R \sigma^{2}}{1+c(\rho+n R) \sigma^{2}} .
$$

Eq. (12) shows that, compared to the case with only one agent $(n=1)$, a situation with many agents sharing a collective bonus calls for a larger reward for an increase in average output per worker. This reflects that, since each individual worker must share his bonus with all the others, a greater reward for an increase in average productivity is needed to induce effort. On the other hand, we see from (13) that the optimal marginal reward for the individual worker's effort becomes smaller in a team with a collective bonus. This reflects that a collective bonus scheme is a less effective means of inducing individual effort when all bonuses generated by an extra individual effort must be shared with the rest of the team.

Thus, if teamwork is particularly important in the public sector because of the character of the outputs produced, and if all members of a public sector team have to be rewarded collectively, it is probably optimal to accept a rather weak link between the individual worker's effort and his income at the margin.

\section{Multiple tasks}

Let us return to the case with only one agent and one principal, but let us assume that the agent spends efforts $e_{1}$ and $e_{2}$ on two different tasks generating stochastic outputs $x_{1}=e_{1}+\varepsilon_{1}$ and $x_{2}=e_{2}+\varepsilon_{2}$. For simplicity, assume that the stochastic components in the two outputs $\left(\varepsilon_{1}\right.$ and $\left.\varepsilon_{2}\right)$ have the same variance, $\sigma^{2}$, and that they follow independent normal distributions. Suppose further that the agent's pay depends in part on the outputs resulting from his efforts, so that his income is

$$
\begin{aligned}
y & =k+m_{1} x_{1}+m_{2} x_{2} \\
& =k+m_{1}\left(e_{1}+\varepsilon_{1}\right)+m_{2}\left(e_{2}+\varepsilon_{2}\right) .
\end{aligned}
$$

\footnotetext{
${ }^{17}$ Trade unions tend to nurture such norms, and as we have seen, they are typically stronger in the public sector.
} 
Following Dixit (2002, p. 705), let the agent's total cost of effort be

$$
C=\frac{c\left(e_{1}^{2}+e_{2}^{2}+2 \alpha e_{1} e_{2}\right)}{2} .
$$

This specification implies that if $\alpha>0$, the marginal cost of effort in one task increases with the amount of effort spent on the other task. In this case the tasks are said to be substitutes: spending more time and effort on one task reduces the possibility of doing a good job in the other task. Conversely, if $\alpha<0$, the two tasks are said to be complements, since the marginal cost of effort in one task will then decline as the agent spends more effort on the other task. In that case it becomes easier to do a good job in the second task if you put more effort into the first task, and vice versa.

The principal values both outputs equally, so his net payoff is now $x_{1}+x_{2}-y$. Maintaining the other assumptions from the basic principal-agent model, it follows from the analysis in appendix A that the principal will choose

$$
m_{1}=m_{2}=m=\frac{1+c(1+\alpha) R \sigma^{2}}{1+c(1+\alpha)(\rho+R) \sigma^{2}} .
$$

Since workers are subject to a time constraint, the case where $\alpha>0$ is probably the more frequent one: if the agent spends more time on one task, he has less total time available, so his marginal disutility from spending additional time on the other task goes up. Eq. (16) then implies that pay should be less dependent on output when agents carry out multiple tasks than when they perform only a single task. ${ }^{18}$ The reason is that, if the agent is induced to perform more of one task, his marginal effort cost of solving the other task will increase (when $\alpha>0$ ), and hence he will want to spend less effort on that task. Therefore the principal will be cautious not to reward a particular task too generously for fear that this may divert too much effort away from the other task. Since this concern applies to both tasks, the end result is that the marginal rewards for both tasks get muted.

Several writers, including Dixit (2002, p. 697), have stressed that multitasking may be more prevalent in the public than in the private sector because of the many different goals public agencies are expected to pursue. If this is correct, and if the case of substitutability between tasks $(\alpha>0)$ is in fact the more common one, the analysis here does suggest that there is less scope for the use of high-powered incentives in the public sector.

\section{Multiple principals and tasks}

As mentioned in section 3.1, public sector organizations typically have many stakeholders whose interests must all be taken into account. The fact that public sector agents often have several tasks may thus reflect that they have several principals. Consider therefore a scenario where one agent carries out two tasks for two different principals, $A$ and $B$.

\footnotetext{
${ }^{18}$ This follows from the fact that (16) implies $\partial m / \partial \alpha=\frac{-c \rho \sigma^{2}}{\left[1+c(1+\alpha)(\rho+R) \sigma^{2}\right]^{2}}<0$.
} 
The two stochastic outputs $x_{1}$ and $x_{2}$ produced by the agent are still given as $x_{1}=e_{1}+\varepsilon_{1}$ and $x_{2}=e_{2}+\varepsilon_{2}$ (with the same assumptions on $\varepsilon_{1}$ and $\varepsilon_{2}$ as before), but now his total income $y$ consists of the sum of the incomes $y^{A}$ and $y^{B}$ received from the two principals. Both principals pay the agent according to a linear pay schedule, but the coefficients in the reward schemes differ because the principals have different preferences for the two outputs. Hence we have

$$
\begin{aligned}
& y^{A}=k^{A}+m_{1}^{A} x_{1}+m_{2}^{A} x_{2}, \\
& y^{B}=k^{B}+m_{1}^{B} x_{1}+m_{2}^{B} x_{2} .
\end{aligned}
$$

The payoffs for principals $A$ and $B$ are $x_{1}-y^{A}$ and $x_{2}-y^{B}$, respectively, so $A$ gets utility from $x_{1}$, whereas $B$ gets satisfaction from $x_{2}$. The two principals do not coordinate, so $A$ chooses his pay parameters $k^{A}, m_{1}^{A}$ and $m_{2}^{A}$ so as to maximize his expected utility, taking the parameters $k^{B}, m_{1}^{B}$ and $m_{2}^{B}$ chosen by $B$ as given, and vice versa. For simplicity, we now assume that the two tasks performed by the agent are neither substitutes nor complements, i.e., the parameter $\alpha$ in (15) is zero. We also assume that the two principals have the same degree of risk aversion.

With these assumptions, appendix A shows that the agent's total marginal reward for additional output in each of the two tasks will be the same and equal to

$$
m=\frac{1+c R \sigma^{2}}{1+c(\rho+R) \sigma^{2}+c \rho \sigma^{2}}
$$

Comparing (19) to (5), we note that the marginal reward for output is muted when there is more than one principal. As shown in appendix A, this is because each principal chooses a negative $m$-coefficient on the output that does not generate utility for him, to induce the agent to shift effort into the other task which generates valuable output for that particular principal. In this way the principals get in the way of each other.

\section{Summing up the lessons from basic principal-agent theory}

In summary, basic principal-agent theory suggests a number of reasons why public sector employers may want to rely less on performance-related pay than private employers. These reasons include a relatively high degree of risk-aversion among public sector employees; external influences on public service output beyond the control of the individual service worker; the difficulty of measuring individual contributions to the output of a team of public service workers; a possible preference for the use of collective rather than individual bonus schemes; the need for public sector workers to perform several different tasks, and the existence of multiple stakeholders who disagree on which tasks should be given priority.

At the same time the models described above also suggest that pay should be related to performance to some extent even in the public sector: none of the models implied that $m$ should be zero. Moreover, the basic principal-agent model also suggested that 
if service output is stochastic and if public sector principals are more risk averse than principals in the private sector - which may well be the case - this will call for a stronger relation between pay and performance in the public sector, ceteris paribus.

However, below we shall discuss some additional factors which may further limit the scope for the use of material incentives for public sector workers.

\subsection{Intrinsic versus extrinsic motivation}

Principal-agent theory assumes that agents will not exert any effort unless they receive a material reward for it. ${ }^{19}$ But as already noted, many people - including many who work for the government - have an intrinsic motivation to carry out a task, e.g. because of a sense of duty, or because doing the job is simply good fun for them. For a long time many social psychologists and other scholars outside the economics profession have argued that the introduction of extrinsic incentives such as pay for performance may crowd out the intrinsic motivation that fosters pro-social behaviour.

The following example, likely to be familar to many parents, illustrates the point: you feel that your son ought to do the family the service of mowing the lawn regularly. He is far from enthusiastic about it, but if you appeal to his sense of duty, he will do it. But some day when he is reluctant, you decide to offer him money to get the work done. After that day you may find that he will never mow the lawn again without getting paid for it. By offering him money, you signalled that it is not really his inherent duty to mow the lawn after all. In this way you destroyed his intrinsic motivation.

Over the years psychologists, experimental economists, and other social scientists have accumulated a lot of evidence that extrinsic incentives may crowd out intrinsic motivation (see the surveys by Frey and Jegen (2001) and Gneezy et al. (2011)). Economists such as Frey (1997), Kreps (1997), Bénabou and Tirole (2003), Besley and Ghatak (2003, 2005) along with many others have argued that this evidence should be taken seriously by mainstream economics, and many economists have followed their lead in recent years.

The literature has emphasized several psychological mechanisms which may explain why extrinsic incentives can harm intrinsic motivation. For example, if an external intervention such as the introduction of performance-related pay is seen by agents as an attempt to control their behaviour, their inner motivation may suffer because they resent being 'manipulated'. Alternatively, agents may conclude that their previous willingness to put in extra effort without being directly rewarded is not really needed, because the new external control mechanism (reward scheme) will ensure that what needs to be done will actually get done. A related possibility is that agents get 'offended' because they interpret the incentive scheme as a signal of mistrust that does not recognize their previous

\footnotetext{
${ }^{19}$ See eq. (4) which implies that $e=0$ if $m=0$.
} 
efforts. It may also be that agents lose self-esteem (and thereby motivation) if they see the incentive scheme as a lack of willingness to acknowledge their intrinsic motivation.

It is actually quite easy to allow for such psychological mechanisms in a principal-agent framework. Suppose an agent has the utility function $u(y-C)$, where $y$ is his income given by our familiar performance-related pay scheme $y=k+m x=k+m(e+\varepsilon)$, and $C$ is his cost of effort. Suppose further that the psychological cost of exerting effort is influenced by the presence of the incentive scheme so that the cost of effort is given by the function

$$
C=C(e, m), \quad C_{e}(e, m)>0, \quad C_{e e}(e, m)>0,
$$

where $C_{e}(e, m)$ and $C_{e e}(e, m)$ are the first and second derivatives with respect to effort. Thus we make the standard assumptions that the marginal cost of effort is positive and increasing in effort. If the utility function $u(y-C)$ displays constant absolute risk aversion, one can show that an agent who maximizes his expected utility will exert effort to the point where the marginal cost of effort equals the expected marginal reward for effort $(m)$ :

$$
C_{e}(e, m)=m
$$

From (21) it follows that

$$
\frac{d e}{d m}=\frac{1-C_{e m}}{C_{e e}},
$$

where the cross-derivative $C_{e m} \equiv \partial^{2} C / \partial e \partial m$ measures the impact of a more high-powered incentive scheme on the marginal cost of effort. The term $1 / C_{e e}$ in $(22)$ captures the usual positive incentive effect stressed by standard economic theory. But if extrinsic incentives tend to crowd out intrinsic motivation, we have $C_{e m}>0$. The term $-C_{e m} / C_{e e}$ in (22) will then be negative, and the sign of $d e / d m$ will be indeterminate, reflecting that stronger material incentives may not work as intended. If the motivation-crowding effect $\left(C_{e m}\right)$ is strong enough, the incentive scheme will backfire $(d e / d m<0)$, and it will certainly dampen any positive net effect on effort.

Many economists, including Pendergast (2011, p. 133), doubt that such perverse effects can occur except in special contexts such as charities. These skeptics often point to Ed Lazear's study of the productivity effects of performance pay on productivity. Using data from a large autoglass company that changed its compensation structures between 1994 and 1995, he found that the introduction of performance pay raised the firm's productivity by anywhere from about 20 to 36 percent (Lazear, 1996). However, Frey and Jegen (2001, pp. 595-596) argue that mounting glass windshields in cars is a simple task environment where one would not expect motivation crowding to occur. Rather, the evidence suggests that such crowding out is more likely to occur when 'interesting' tasks are involved, and in environments where personal relationships involving reciprocity, 'gift exchange' and altruistic behaviour play a role. 
Still, several other empirical studies of performance pay and our example with the transportation of British criminals to Australia suggest that in many contexts, monetary incentive schemes $d o$ work as intended: if you pay people to do things, they will do more of it. The evidence surveyed by Frey and Jegen (2001) and Gneezy et al. (2011) also includes cases where extrinsic incentive schemes seem to have had a positive crowding-in effect on intrinsic motivation (i.e., cases where $C_{e m}<0$ in our notation). This may occur if the extrinsic incentive is seen by agents as supporting the norms underlying their intrinsic motivation. An example may illustrate how positive motivation crowding could occur: Suppose a university department decides to use part of the funds available for pay rises to grant bonuses to staff members for their publications in top journals. If the other staff members feel pride on behalf of the department when some of their colleagues get exposure through prestigious publications, such a bonus scheme may well strengthen the individual staff member's inner motivation to do high-quality research.

The point is that motivation crowding effects are context-specific. In many cases a negative effect of extrinsic on intrinsic motivation may not occur at all; in some cases the effect may even be positive, but in other cases an unintended crowding-out effect will pop up. Hence performance pay is an instrument that should be used with care; successful use may require considerable psychological insight on the part of managers. This conclusion holds for the private as well as the public sector, but it may be particularly relevant in the latter. As mentioned in section 2.2, there is some evidence in favour of Tim Besley's and Maitreesh Ghatak's hypothesis that people with a particular preference for the missions of public sector organizations select into public sector employment (Besley and Ghatak (2003)). If public sector workers derive much of their motivation from the pro-social missions that often characterize public organizations, there may be many cases where high-powered monetary incentives could have a negative crowding effect on intrinsic motivation in the public sector.

\section{Performance measurement and yardstick competition}

If government employers wish to base (part of) the pay of public managers and workers on their performance, they will obviously need to measure it. Even if pay is not based on performance, there may be other reasons why performance measurement may be useful. This section reviews the purposes and pitfalls of performance measurement. It also discusses how the performances of comparable government agencies may be benchmarked against each other and how that might help to improve average performance. 


\subsection{The rationale for performance management}

Throughout the OECD area, governments try to measure the performance of their agencies, although practices and ambitions in this respect differ widely. A Policy Brief from the OECD (2004) explains how information on performance can help governments manage and control public services, enable parliaments to check whether taxpayers are getting value for money from public agencies, and help citizens to keep governments and their agencies accountable for their actions.

Ideally, one would like to measure performance by the final outcomes of government activities. Does the police force offer effective protection against crime? Does the health care system ensure that citizens are in good health? Does the education system provide students with skills that will make them productive workers and responsible citizens? Do public job centres actually manage to get the unemployed back into jobs? etc. However, many aspects of such outcomes are hard to measure in quantitative terms, and they also depend in large part on circumstances beyond the control of individual public agencies. Hence the auditors of government agencies often resort to measuring their outputs: How many arrests did the police make, and how many criminal cases did they manage to solve? How many hospital treatments of different kinds did public hospitals carry out? How many classroom hours did teachers produce? But the trouble with many data on public sector output is that they do not necessarily tell much about the quality of the services delivered. And even worse: data on many important outputs of government agencies are scarce, so quite often auditors have to rely on statistics on inputs into public production that are believed to be positively correlated with outputs and outcomes, e.g.: What are the numbers of teachers per student at different levels of education and across different educational institutions? What is the average number of nursery assistants per child in public kindergartens? What is the ratio of doctors and nurses to the number of citizens in need of treatment? etc.

If we are interested in measuring the welfare of citizens, we should obviously focus on data on outcomes, in so far as they are available. If we want to measure the contribution of public agencies to citizen welfare, it may be more relevant to focus on their outputs, but then we should try as much as possible to adjust for changes in service quality. Focusing on the evolution of inputs into public service production seems a third-best option to which we may have to resort in case of missing data on outcomes and outputs. In any case, when measuring the performance (effectiveness) of public sector agencies, we should consider the ratios of their outcomes, outputs and/or quantitative inputs to their expenditures to evaluate their ability to create value for money. And for a fair judgement of performance, we should acknowledge that the environments of individual public agencies may differ a lot, so any two public sector units delivering the same kind of service may not be able to generate the same outcome or output per euro expended, even if they are equally competent and dedicated to their task. In the next subsection I 
will discuss how this problem of performance measurement may be addressed.

The relevant level of aggregation and detail of performance measures depends on who is going to use them. The measures that the central government needs in order to evaluate the performance of local governments will probably differ from the measures that the individual public manager will find useful in the management of his organization. Behn (2003) discusses how public managers may use performance measurement to improve their management practices. He stresses that the ultimate motive for measuring performance must be to find ways to improve it. For this purpose the manager must develop performance measures that will help him to evaluate how well his agency is currently doing, ensure that his subordinates are doing the right things, direct the agency's allotted funds towards the most effective programs and projects, motivate line staff, middle-managers and other stakeholders, promote the agency vis á vis political superiors and the general public, celebrate the agency's successes, and learn which of the agency's practices that work and which that do not. For each of these purposes the manager may need different performance measures, so Behn (2003, p. 599) warns against "the futile search for the one best measure".

\subsection{Yardstick competition and benchmarking}

In so far as comparable public agencies use similar performance measures, these measures will help voters and other principals to compare performance across agencies and jurisdictions. If the local service-producing units in some municipality seem to perform badly compared to similar units in neighbouring municipalities, local voters may conclude that local politicians are doing a poor job and may not want to reelect them. Knowing this, the politicians will be more keen to ensure a good performance of local public sector institutions. In this way performance measurement may help to create a healthy yardstick competition across jurisdictions. ${ }^{20}$

This was the purpose when the UK Department of Health introduced the Social Services Performance Rating (SSPR) in 2002. The SSPR provided an annual statistical overview of the performance and rating of a number of social services delivered by the local councils. According to Revelli (2006, p. 461), who quotes the Social Services Inspectorate (2002), the objective of the SSPR was 'to ensure that social care issues are properly addressed, to promote good practice and to identify councils that are performing poorly (. . .) The ratings are intended to improve public information about the current performance of services (. . .) People have a right to know how well their councils are performing in meeting these responsibilities, whether they are receiving such services themselves, have a family member receiving such services, or are a council tax payer'.

\footnotetext{
${ }^{20}$ It may also create yardstick competition across similar units within each jurisdiction, since it enables local politicians to compare the performance of individual public managers in each service area.
} 
There is a large literature on yardstick competition and several empirical studies suggesting that such competition does in fact take place in many countries (see, e.g., Besley and Case (1995a, 1995b), Heyndels and Vuchelen (1998), Schaltegger and Kuttel (2002), Bordignon et al. (2003), Revelli (2006), Revelli and Tovmo (2007)). One might think that yardstick competition can never harm citizen welfare and will generally improve it. Unfortunately things are not that simple. As Besley and Smart (2007) have shown, the effect of yardstick competition on voter welfare is theoretically ambiguous. To illustrate, suppose there are only two jurisdictions, A and B. If politicians in B are good at creating value for their taxpayer's money, yardstick competition will make it harder for bad politicians in A to remain in office. This should help to improve voter welfare in A. But if the politicians in B are incompetent or malevolent, resulting in poor public services in B, voters in jurisdiction A may choose to reelect their own mediocre politicians, since they do not seem to be so bad compared to those in B. In this situation yardstick competition actually helps incompetent politicians in both jurisdictions to stay in office.

This ambiguous welfare effect of yardstick competition stems from the voters' imperfect information: they cannot easily figure out if their elected politicians are competent, because voters do not know the true cost of producing public services. Hence voters look to other jurisdictions to see how much service other politicians are able to deliver, but this is an imperfect signal of the relative competence of local politicians because their colleagues across the border may face a different cost of public service production.

These observations suggest that yardstick competition would work better if voters had more information on best practices in the various areas of public service production. If voters knew how much service the best-performing public sector units (in the relevant area of comparison) would be able to produce per dollar spent if they were placed in the local jurisdiction, it would be easier to evaluate the skills of local politicians and their officials.

Such information on best practices can be obtained by combining performance measurement with systematic benchmarking of local jurisdictions against each other. ${ }^{21}$ But then one must confront two major challenges head on. The first one is that of separating the effect of exogenous influences on service cost and quality from the impact of factors that politicians and public sector employees can actually control. If performance benchmarking is to be fair, it must focus on the latter. The second challenge, often overlooked, is to design indicators of service quality that allow local jurisdictions to put different weights on different aspects of quality, depending on local circumstances and preferences. After all, one important motivation for having local governments and granting them some autonomy is that this helps to tailor public service provision to local needs and preferences.

\footnotetext{
${ }^{21}$ Bogetoft (2012) reviews alternative methods of performance benchmarking and Worthington and Dollery survey techniques of performance benchmarking of local governments.
} 
In a study of public service production in Danish municipalities undertaken for the Danish Productivity Commission, Wittrup et al. (2013) have applied a method of benchmarking that seeks to meet these challenges. The study uses Data Envelopment Analysis to identify best municipal practices in various areas of local public service provision such as primary education, day care for children and care for the elderly.

The basic idea of Data Envelopment Analysis is illustrated in figure 4 (based on hypothetical data). Along the horizontal axis we measure the cost of service provision per client in some local public service area, e.g., primary education (in that case the "clients" would be the local school children). Along the vertical axis we measure some aggregate indicator of the service level offered in that particular service area. The blue dots in the figure are the observed combinations of cost and service level in various municipalities. The dotted green line is the envelope curve identifying the best practice in the sense that no municipality has been observed to have a more favorable combination of cost and service level (lower cost at the same service level or higher service at the same cost) than the combinations defined by the curve. Suppose now that we want to measure the scope for improvement in the municipality represented by the black dot in the figure. If we want a monetary measure, we can use the horizontal distance from the black dot to the best-practice frontier. This distance measures how much money per client the municipality could save without reducing service quality if it were just as efficient as the most efficient municipalities.

Figure 4. Benchmarking against best practice

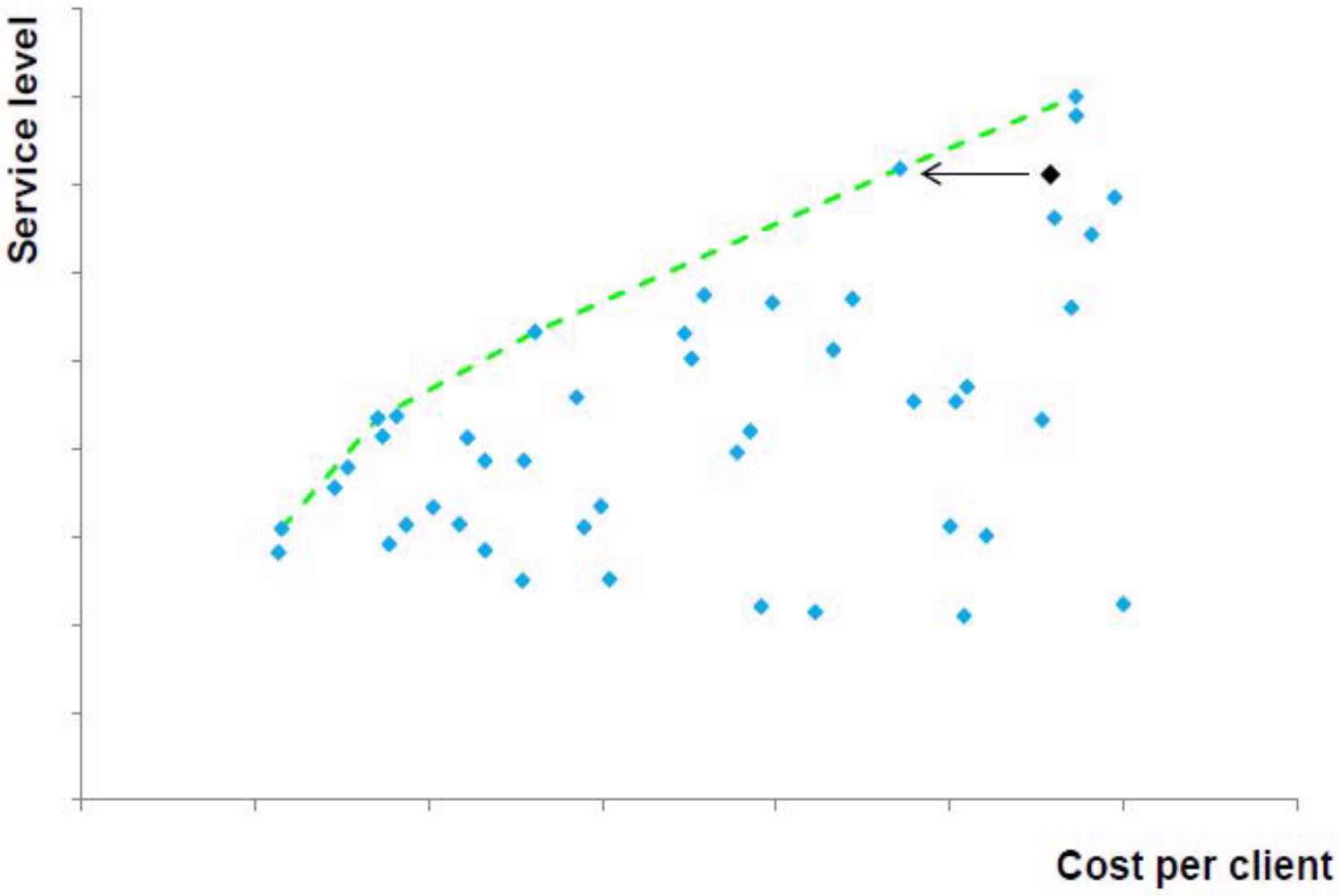


But how do we measure the service level and the cost of providing it in a way that addresses the two basic challenges mentioned above? As for the service level, Wittrup et al. (2013) opt for the so-called Benefit-of-the-Doubt (BoD) index surveyed by Cherchye et al. (2006). For any given service area, the authors identify a number of quantitative indicators which are generally considered to be positively correlated with the quantity or quality of service delivered. Depending on data availability, these indicators may reflect outcomes, outputs or inputs. The indicators are weigthed together to obtain an aggregate index of the service level. Let $y_{i}^{m}$ denote the observed value of indicator $i$ in municipality $m$ and let $w_{i}$ be the weight assigned to this indicator. Suppose further that there is a total of $n$ indicators and $M$ municipalities. When calculating the "pure" BoD index of service performance $S^{m}$ for municipality $m$, the weights of the various service indicators are then found by solving the following linear programming problem:

$$
\text { Maximize } S^{m}=\sum_{i=1}^{n} w_{i} y_{i}^{m} \text { with respect to } w_{i}, \quad i=1, \ldots, n
$$

subject to the constraints

$$
\sum_{i=1}^{n} w_{i} y_{i}^{h} \leq 1 \text { for all } h=1, \ldots, M, \quad w_{i} \geq 0 \text { for all } i=1, \ldots, n .
$$

Thus the BoD index for municipality $m$ maximizes the weighted sum of its service indicators subject to the constraint that no municipality can attain a weigthed sum greater than 1 when the same weights are applied to the observed values of its indicators. If $S^{m}=1$, it means that no other municipality has attained a higher service level, given the chosen weights. On the other hand, if $S^{m}<1$, there is at least one other municipality that has achieved a higher service level than municipality $m$. But municipality $m$ is given the benefit of the doubt in the sense that, when it is benchmarked against other municipalities, the auditor in charge of the benchmarking chooses the weight of each service indicator in a way that will place the relative service performance of municipality $m$ in the most favourable light. Specifically, the auditor assigns greater weights to indicators where municipality $m$ has scored well relative to other municipalities. The justification for this procedure is that if a jurisdiction has a high score on certain indicators, it is probably because local voters assign particular importance to those aspects of service quality. In this way the $\mathrm{BoD}$ index respects the rights of individual municipalities to express their local political preferences through the way in which they structure their service provision.

Two further attractive properties of the BoD index should be mentioned. First, by allowing for many different service indicators within a given service area, it acknowledges that no single indicator is likely to capture all of the aspects of service provision that citizens value. By incorporating many indicators, it is possible to account for multidimensional goals in each service area. Second, the BoD index is invariant to a proportional 
rescaling of the indicators. Thus, the units in which the indicators are measured do not matter for the value of the overall index.

The procedure in (23) and (24) for calculating the weights of the individual service indicators gives the individual municipality the maximum benefit of the doubt. For example, the weight attached to an indicator where a municipality has a very low score could well be zero. However, the central government may have limited tolerance for variations in the character of services offered by local governments. A desire to limit the differences in the treatment of citizens across municipalities could be accomodated by adding the following additional constraints to the maximization problem in (23) and (24):

$$
a_{i} \leq w_{i} y_{i}^{m} \leq b_{i} \quad \text { for all } h=1, \ldots, M, \quad \text { and all } i=1, \ldots, n .
$$

Because of the constraint in $(24), w_{i} y_{i}^{m}$ will always fall between zero and one. The constants $a_{i}$ and $b_{i}$ in (25) are numbers in the unit interval that further constrain the permissible variation of the weight of each individual service indicator in the overall $\mathrm{BoD}$ index. The closer $a_{i}$ and $b_{i}$ are to each other, the smaller is the scope for variation, so the higher is the priority given to equal treatment of citizens, and the lower is the degree to which individual municipalities are given the benefit of the doubt. In their benchmarking of Danish municipalities, Wittrup et al. (2013) incorporate constraints of the form (25) where $a_{i}=1 / 2 n$ and $b_{i}=2 / n$. Thus, in a service area with, say, five service indicators $(n=5)$, the weight of the individual indicator in the BoD index can vary between 10 percent and 40 percent. In the end, choosing the limits $a_{i}$ and $b_{i}$ is a political trade-off that the authority in charge of the benchmarking (or its principal) must make.

The service level offered by a municipality must be held up against the cost of providing it. To control for exogenous cost drivers, Wittrup et al. (2013) deflate the actual cost per client by the expected cost. The latter is calculated from a regression analysis explaining the variation in cost per client across all Danish municipalities by differences in various demographic, socioeconomic and geographical factors. Thus the cost per client measured along the horizontal axis in figure 4 is really the actual cost as a ratio of the cost per client one would expect in each municipality, given its particular demographic, socioeconomic and geographical structure, and given the average impact of these variables on the cost of service production. In this way the measure of cost accounts for differences in production conditions that are difficult for the individual municipality to control. However, acknowledging that their regression analysis probably does not capture all relevant exogenous cost drivers, Wittrup et al. (2013) suggest that a benchmarking exercise should only include a group of municipalities which are not too different from each other in terms of demographic, socioeconomic and geographical characteristics.

Armed with these measures of service levels and costs, the auditor can now identify and quantify the potential for efficiency improvements in each municipality. As mentioned, the measure of cost recorded along the horizontal axis in figure 4 is $C / C^{e}$, where 
$C$ is actual cost per client and $C^{e}$ is the expected cost per client. If the measured horizontal distance to the best-practice frontier in figure 4 is, say, $d$ for some municipality, the absolute amount of money per client that the municipality could save by adopting best practice would then be equal to $d \cdot C^{e}$.

Benchmarking by means of the BoD index will not only help to expose potentials for productivity improvements; it should also encourage individual jurisdictions to learn from each other by giving each of them the benefit of the doubt. If municipality B scores better than municipality A even when the service level index gives the largest weights to indicators that are given high priority in A, local politicians and public managers in $\mathrm{A}$ should be more motivated to investigate and possibly import the practices of municipality B.

\subsection{Second thoughts: the performance paradox}

The previous subsection described a method of benchmarking that should stimulate learning and help to make yardstick competition work well. Several other methods of intelligent benchmarking are also available, as described in the handbook of the OECD and the European Commission (2008). ${ }^{22}$ As Behn (2002, p. 6) has emphasized, the objective of performance management in the public sector is to move from process-oriented and ruledriven management to performance-oriented and results-driven management that will create greater value for citizens. Yet many writers and critics of the New Public Management have argued that performance measurement and management may not work as intended and that performance may actually worsen the more you try to measure it. This is the so-called performance paradox discussed by van Thiel and Leeuw (2002). Below I will briefly review some reasons why performance measurement may turn out to be ineffective or even counterproductive.

\section{Lacking motivation}

It is hard to argue against the general proposition that governments ought to be held accountable for their performance. That is why we have so much performance measurement - at least on paper. But in reality the politicians who are expected to demand it and the public employees who are expected to deliver it may not really want performance to be meticulously measured. The policiticians who are supposed to set the goals and targets of public agencies may prefer to keep them broad and elusive rather than stating them very precisely. Goals that are more clear are often also more controversial and harder for politicians to agree on. Clearer goals are supposed to make it

\footnotetext{
${ }^{22}$ Ballanti et al. (2014) note that policy makers have been reluctant to embrace relatively complicated benchmarking techniques based on Data Envelopment Analysis. They suggest a simpler (but quite elegant) method for monitoring the performance of local governments that relies on the same data as those used in fiscal equalization schemes.
} 
easier to detect poor performance, but sometimes this may be politically inconvenient if it puts stronger pressure on politicians to take action against strong interest groups that extract rents from the public sector. Moreover, because of term limits on public office and looming elections, politicians tend to have short horizons. Yet it may take several years or even decades before a public agency can realistically be expected to deliver on specific targets set up for them, so why should politicians bother to spell out goals and targets in detail? ${ }^{23}$ For a politician seeking (re)election, it may be more useful to formulate "grand visions" with broadly stated goals rather than detailed policy schemes specifying who is supposed to do what for whom within which time horizon.

All of this is not to say that politicians will never set clearly formulated performance targets. It is only to say that they may not have strong incentives to do so. A possible reaction to this problem could be to delegate the choice of more specific performance targets to the managers and employees of individual public agencies. Such empowerment of public employees could strengthen their commitment to the goals of their organization and increase their motivation, thereby improving performance. Working in the other direction, it may be more difficult to hold individual public sector units accountable for their performance when goal setting is decentralized. In a recent study which carefully controls for the influence of other factors, Nielsen (2013) finds that decentralizing goal setting in the Danish primary education sector has actually tended to weaken performance, measured by student grade points in nationally standardized tests. This is not encouraging for those who hope that decentralization may strengthen performance.

Furthermore, if politicians often prefer vague and ambiguous goals to more precise ones (even if they pay lip service to performance management), what is the incentive for public managers and employees to engage in detailed performance measurement? Indeed, with more precise performance measures, managers and employees may worry that there is a greater risk that they will be punished in some way if their organization scores poorly (Behn, 2002, p. 12). Alternatively, public employees can "sabotage" a performance audit if they consider it an act of distrust (van Thiel and Leeuw, 2002, p. 274). More generally, public managers and employees may not trust a promise that if they submit to stricter performance measurement, they will be given more flexibility to meet the performance targets. As emphasized by Behn (2002, p. 15), even high-ranking government officials can rarely credibly promise their subordinates that from now on they will be subject to fewer rules regarding procurement, personnel, budgeting, work processes etc., since there are many reasons - some rational and some less rational - why such rules have been

\footnotetext{
${ }^{23}$ True, president Kennedy's 1961 speech committing the U.S. to land a man on the moon before the end of the decade was an example of a specific target with a fairly long horizon. But it also had the flavour of a "grand vision" capturing the imagination of ordinary people. Most detailed targets and instructions for public agencies do not have that characteristic if they are meant to be useful. Rather, they will have a technocratic character appealing only to individuals with a specific interest in the details of particular types of public service production.
} 
introduced (see the discussion in section 7). So front line workers and their immediate superiors may have good reasons to fear that more specific performance targets will just add another layer of paperwork on top of an already big pile of reporting requirements.

In sum, despite a general agreement that governments and their agencies should be held accountable for their actions, there are many reasons why politicians and public sector employees may not be keen to embrace performance measurement. Obviously this reduces the likelihood that it will work as intended.

\section{Unintended side effects}

Even if performance measurement is adopted without prejudice, it may still fail to deliver improved performance and may even worsen it. Perhaps the greatest pitfall is that what doesn't get measured doesn't get done. If some activity is used as an indicator of performance, you are likely to see more of that activity. The problem is that this may happen at the expense of some other activity which is also important but which is not included in the performance audit because it cannot be measured, or at least cannot be measured in quantitative terms. In that case performance measurement distorts the incentives of public organizations. The net effect on social welfare may still be positive if the most important outcomes or outputs are easy to measure and the unmeasurable ones are less important. But this may not always be the case, and then you get unintended side effects of performance measurement such as suboptimizaton and "tunnel vision" where public agencies focus too narrowly on optimizing the activities for which they are credited in performance audits. For example, if school performance is measured only by the ability of pupils to perform in certain standardized and narrowly defined tests, teachers may focus excessively on "teaching to the test" at the expense of other learning activities that society might also want schools to carry out.

A related problem is that rigorous performance measurement, when coupled with fears that poor performance will be punished, may induce public organizations to engage in "cream skimming" or "cherry picking". This is the tendency to concentrate service efforts on those groups of clients who are most easy to service or treat so that performance targets are more easily met. This may lead to underprovision of services to individuals who are difficult to help, e.g., long-term unemployed persons with severe social problems, the cronically ill, etc.

When combined with a lack of motivation, the typical asymmetry of information between principals and agents may also make performance measurement ineffective. If the manager and/or the employees in a public sector unit do not feel that the performance measures imposed on them from above are really the most relevant ones, they will be tempted to engage in "gaming". That is, they will pretend to measure their performance by the indicators dictated to them, and may even come up with some nice numbers that the relevant principal is not really in a position to verify, and then they will continue 
doing business as usual. ${ }^{24}$

Yet another problem is that, in practice, many attempts to introduce refined performance measurement seem to have resulted in more bureaucracy, even though the idea of the "big bargain" of the New Public Management was to offer more flexibility and less red tape in return for more rigorous measurement of performance. Van Thiel and Leeuw (2002) talk of an "audit explosion" which has led to a strong increase in the number of regulators and auditors in OECD countries, according to the evidence they cite. This appears to confirm the concerns of those who fear that performance measurement just adds new layers of bureaucracy on top of existing ones.

The risk of creating more bureaucracy increases if performance measurement leads to a proliferation of performance goals and indicators over time. Once the idea of measuring performance on a recurrent basis is accepted, it is not surprising if the relevant principals come to think of new criteria for good performance which they would also like to measure in addition to the existing ones. In Denmark, Binderkrantz and Christensen (2009) found that the number of targets in the performance contracts between central ministries and their agencies increased by 85 percent between 1995 and 2005. With an ever-growing number of performance measures, public managers and their principals may end up with the so-called DRIP syndrome - Data Rich but Information Poor (Behn, 2003, p. 592). This is a situation where the mass of performance indicators is so big and diversified that it is difficult to extract useful information from them - one cannot see the forest for the trees. ${ }^{25}$

As the number of diverse goals and targets in performance contracts increases, it may become more difficult to determine whether performance is good or bad - different indicators may point in different directions and it may be unclear which indicators are the more important ones. In practice, having many goals may be equivalent to having no goals and may undermine the ability of principals to hold public agencies accountable for their performance. Perhaps reflecting this, or maybe due to the phenomenon of "gaming" mentioned earlier, Binderkrantz and Christensen (2012) were unable to detect any systematic relationship between the performance of Danish central government agencies and the bonuses paid to their managers under performance contracts.

These problems, overwhelming as they may seem, do not imply that performance measurement should be given up - after all, if public agencies are to be held account-

\footnotetext{
${ }^{24}$ Sir Josiah Stamp (1927) gave an early warning against gaming when he wrote: 'Public agencies are very keen on amassing statistics - they collect them, add them, raise them to the nth power, take the cube roots, and prepare wonderful diagrams. But what you must never forget is that every one of those figures comes in the first instance from the village watchman, who just puts down what he damn pleases.' Baker (1992) offers a theoretical analysis of the "gaming" problem related to performance measurement.

${ }^{25}$ Perhaps in recognition of the DRIP problem, the central ministries in Denmark have actually started to cut back on the number of targets in the performance contracts negotiated with their agencies after 2005.
} 
able, we must evaluate their performance in some way. While there is no easy way to escape the pitfalls mentioned above, empirical research by Moynihan and Ingraham (2003) suggests that performance measurement can be made to work well (in the sense of helping to improve performance) if it is designed well. Key design elements that seem to increase the likelihood of success are a strong focus on measuring results for citizens, including the quality of the service, a strong link between the various components of the performance measurement system, including information exchange and utilization, and avoidance of overly complicated performance measures. However, the available evidence and experience indicates that, like performance-related pay, performance measurement is an instrument that needs to be used with care.

\section{Introducing competition in the public sector}

As a supplement to yardstick competition, governments have also tried to improve performance by introducing "genuine" competition in the public sector, most frequently through various voucher schemes and through outsourcing of public service provision via competitive public tender. This main section discusses how such instruments work in theory and practice.

\subsection{Vouchers}

Vouchers, surveyed by Valkama and Bailey (2001), are found in the private as well as the public sector. In the public sector, a voucher gives the holder a right to receive a certain amount of some public service free of charge or at a subsidized price. A voucher need not take the physical form of a document (a "coupon"); it may just be a legally defined right to receive the public service if some objective criteria are met. A key feature of vouchers is that users may choose among alternative certified suppliers of the service. The suppliers may be public sector units, private firms, or a combination of the two. The freedom of choice may be a goal in itself, but it also introduces competition. The hope is that this will improve service quality, strenghthen cost control, and stimulate innovation and entrepreneurship internally in the public sector as well as externally among private service providers.

OECD central and local governments have used voucher schemes in many important areas of public service provision, including some parts of the education and health care sectors, care for children and the elderly, etc. Voucher schemes encourage public service providers to compete on quality but not on price, as the price of the service is typically set at a common level for all providers by the public agency that pays for their services. Valkama and Bailey (2001, p. 43) point out that voucher schemes are likely to work most effectively when the following conditions are met: (i) The preferences of public 
service users differ significantly, and these differences are recognized as legitimate. (ii) Service users are well-informed about market conditions and have an incentive to shop energetically to find the best supplier of the service. (iii) There are many competing service suppliers, or start-up costs are low so that the market is fully contestable even if there are only a few suppliers. (iv) Service users can easily assess and determine the quality of the service. (v) The service is relatively inexpensive and purchased frequently, so users learn by experience. In short, heterogeneous preferences, low transactions costs and low barriers to entry increase the likelihood that vouchers will improve efficiency.

The more the above conditions fail to be met, the weaker is the case for a voucher scheme. Indeed, vouchers may sometimes reduce overall productivity in public service provision, as pointed out by the Danish Productivity Commission (2014a, ch. 5). Vouchers may increase administrative costs, especially if they are means-tested, and they may make public budgeting and the planning of public production capacity more difficult. The authorities are usually obliged to ensure that all citizens entitled to a given service can actually be serviced. Since it may be difficult to predict how many users/clients will be served by private providers, the authorities may have to keep a larger public production capacity in reserve than would be needed if users had no choice between public and private suppliers. Further, the co-existence of many public and private suppliers may hamper effective coordination of services and the utilization of economies of scale.

All of these observations relate to the efficiency aspects of voucher schemes. But concerns about equity have also played an important role in the debate on vouchers. In the health care sector some countries have introduced opt-out vouchers allowing people on a waiting list for public medical treatment or nursing to "jump the queue" and choose a private health care provider who can offer faster treatment. In that case the local authority will pay the private provider an amount equal to the average cost of the relevant treatment in the public health care system, and the citizen will then sometimes have to top up this payment in cases where private health care is more expensive. While such opt-out vouchers may seem to involve a Pareto improvement, they have been criticized for violating the basic welfare state principle that all citizens should have equal access to health care.

Equity concerns have also been prominent in the international debate on education vouchers. In particular, critics (e.g., Ladd, 2002) have argued that universal education vouchers will create selection and segregation effects that will hurt disadvantaged students. Epple and Romano (1998) present an interesting theoretical analysis that speaks to this debate. They set up a model in which tuition-free public schools co-exist with competing, tuition-financed private schools. Public and private schools are assumed to be equally effective in delivering education when given the same inputs and the same group of students. Students differ in their ability and in their family's income. A student's achievement depends not only on his own ability; ceteris paribus he/she will perform bet- 
ter the higher the average ability of his/her peers in the classroom - a well-documented peer effect. This provides an incentive for private schools to structure their tuition fees so as to attract high-ability students, since they thereby become more attractive, allowing them to charge higher average fees. Thus, private schools attract high-ability, low-income students by offering them tuition discounts and/or fellowships. In the equilibrium of this model, the public schools end up with students with a relatively low average ability, and there is a hierarchy of private schools with different average student abilities and tuition fees. Because the demand for education increases with income, students with higher family incomes tend to get concentrated in the private schools. When school vouchers are introduced in this environment, the private schools expand because more able students from low-income families can now afford to switch from public to private schools. These students experience a gain from the introduction of vouchers, but the students left behind in the public schools - those with relatively low income and ability - lose out because of a negative peer effect on their attainment as more able students switch to private schools. At the same time a calibrated version of the model suggests that vouchers will have a moderate positive effect on average welfare and educational achievement.

This analysis by Epple and Romano (1998) suggests how universal school vouchers may lead to increased social stratification and a poorer quality of public schools. Without embracing school vouchers, Ladd (2002) argues that such negative effects could be reduced if vouchers are means-tested and if private schools are restricted in their tuition policies.

As this discussion shows, education vouchers must be carefully designed if one wants to minimize undesirable segregation effects. Vouchers for education remain a contentious issue. Belfield and Levin (2005) argue that their design must reflect a trade-off between four important social goals: (i) freedom of choice, (ii) efficiency, i.e., maximization of educational outcomes for any given resource constraint, (iii) equity, i.e., equal access to education, and (iv) social cohesion, i.e., a common educational experience that will encourage all students to become full participants in the social, political and economic institutions of society. Trading off these worthy goals against each other is obviously not an easy task.

\subsection{Outsourcing via competitive public tender}

Under voucher schemes there is a continuous ongoing competition among public service providers to attract "customers". The price of the service is determined by the relevant public authority, so service suppliers compete on quality. An alternative model of public service provision is to arrange a competitive public tender where potential private and public service providers make a bid for a contract that will give the winner the sole right to deliver a certain public service within a specified time period. Usually this exclusive right is given to the supplier offering to deliver a specified amount and quality of output 
at the lowest price, but it may also be given to the bidder offering the most attractive combination of price and quality. Under this model of service provision there is price competition (or competition on price and quality) at the time of the public tender, but during the contract period the winner of the competition has a temporary monopoly.

In principle, the potential private and public suppliers compete for the contract on equal terms, provided the bid submitted by the incumbent public supplier reflects all relevant costs of delivering the service, including overhead and capital costs. In principle, it will then be immaterial whether the contract is signed with a private provider or with the incumbent public provider, as long as the right to deliver the service is given to the provider who can produce the service (of a given quality) at the lowest cost. In practice, it may be impossible to level the competitive playing field for private and public providers, for two reasons. First, it may be very difficult to allocate all relevant overhead and capital costs to the individual public sector production unit, since these costs are often hidden in the budget for the central administration of the relevant jurisdiction. Second, public sector organizations are rarely allowed to go bankrupt (in fact, it may not be legally possible for them to do so) and will therefore be subject to lower pressure from market forces. These factors may explain why public authorities often decide in advance to outsource service provision to a private provider, without allowing the incumbent public provider to participate in the public tender.

Outsourcing has been a common practice of central and local governments in the OECD area for many years, but its merits or demerits are still disputed. ${ }^{26}$ Proponents emphasize that the competition involved in outsourcing via public tender helps to identify the least-cost and best-practice providers to the benefit of taxpayers. They also argue that the mere possibility of outsourcing helps to keep incumbent public service providers on their toes, thereby improving efficiency even if outsourcing does not actually take place. Further, they argue that a for-profit provider has a stronger incentive to minimize cost than a public provider.

Opponents argue that the additional transactions costs necessitated by outsourcing are often overlooked; that the profit motive may induce private providers to lower service quality in order to save costs, that private providers have a higher cost of capital because of the risk premium required by private investors, and that the cost savings from outsourcing that may nevertheless be observed typically stem from lower service quality and/or lower wages or poorer working conditions for service workers.

Below I will describe a simple model of outsourcing incorporating these elements. The model seeks to clarify some key trade-offs that policy makers will face - and the parameters defining the terms of this trade-off - when they decide whether or not to outsource the provision of some public service.

\footnotetext{
${ }^{26}$ The arguments on both sides of the debate have not changed very much since Jensen and Stonecash (2005) wrote their survey.
} 


\section{A simple model of outsourcing}

The model is described in detail in appendix B. It is a variant of the principalagent model with costly verification of effort set up in Knabe and Sørensen (2006), but I make more specific assumptions on preferences and technology which allows me to derive sharper predictions from the model.

In the model a government principal such as a municipality pays an agent to provide some service to citizens. Under in-house provision, the agent is a public service worker; under outsourcing he is a private entrepreneur. In both cases the agent has the same exogenous outside option which means that the principal must offer him the same minimum level of expected utility to secure the provision of the service. In addition to the (wage) payment needed to secure the participation of the agent, the cost of providing the service includes a fixed overhead cost and a cost of monitoring service quality. Under in-house provision, the fixed overhead cost is borne by the principal; under outsourcing it is carried by the entrepreneur. The quality-adjusted amount of service delivered to citizens is directly proportional to the effort exerted by the agent. For the public service worker, the cost of effort is given by eq. (2) above. Because effort is costly, the public service worker has no incentive to make any effort to reduce the cost of service provision. By contrast, a private for-profit provider has such an incentive, so he divides his effort between servicing the clients and reducing his fixed overhead cost, say, by carrying out some of the firm's administrative work himself rather than hiring someone else to do it. The private provider thus engages in two tasks, and his cost of effort is given by eq. (15) above, with $\alpha>0$. This assumption on $\alpha$ means that the two tasks are substitutes competing for the agent's attention and effort. The principal can observe the level of service quality by incurring a monitoring (audit) cost. If the quality (and, by implication, the agent's effort) is found to fall short of some exogenous benchmark level, the agent is punished by a fine which is proportional to the shortfall. If service quality is found to exceed the benchmark level, the agent is rewarded by a bonus proportional to his "overperformance". An audit of service quality occurs with some probability $p$ determined by the principal. The agent's realized utility is a concave function of his income net of the cost of effort. The agent maximizes his expected utility, accounting for the probability that an audit will occur. The optimal effort will then be an increasing function of the audit probability $p$, so by adjusting $p$ and the associated monitoring cost, the principal can indirectly control service quality.

In this set-up one can identify the factors which will determine whether there is a social gain from outsourcing. This can be done by assuming that, under both modes of provision, the principal chooses an audit probability that will ensure that actual service quality equals the benchmark level. The utility of the citizen clients will then be the same in both cases. In that situation outsourcing will yield a social gain if it allows the principal to secure the provision of the benchmark service level at a lower net budgetary 
cost than the cost of in-house provision. Whether such a gain will actually occur turns out to depend on the balance of the following effects (see eq. (B.33) in appendix B):

Competition effect. Even if the private provider does not make any effort to reduce his overhead cost, outsourcing via public tender may still reduce the fixed cost of service provision by helping the principal to find the most effective supplier. This is the gain from competition emphasized by the advocates of outsourcing. However, the model also allows the possibility that the competition effect (as defined here) could be negative, say, if the public provider has a lower fixed cost per unit of service because of economies of scale, or if the cost of capital is significantly higher for a private than for a public provider.

Ownership effect. This effect, which might also be termed an incentive effect, arises from the fact that the private entrepreneur is the residual claimant to any gain from lower costs of production. This gives the private provider an incentive to engage in cost-saving measures, including measures to reduce overhead costs. Under in-house provision there is no such incentive because the in-house provider is not the residual claimant to the gain from cost savings. According to the model, the ownership effect therefore makes an unambiguously positive contribution to the gain from outsourcing.

Transactions cost effect. By contrast, this effect detracts from the gain from outsourcing, for two reasons. First, to reap the potential gain from the competition effect, a public tender must be implemented at regular intervals, and there is a fixed transaction cost of organizing a tender. Second, because a private provider has an incentive to divert effort away from servicing the clients toward cost-saving activities, the principal must incur larger monitoring costs to secure the same service quality under outsourcing as under in-house provision. The model thus addresses the concerns of those who fear that outsourcing will lead to lower service quality. Unless the principal is prepared to intensify monitoring, quality will indeed deteriorate. ${ }^{27}$ However, the higher the rate of penalty imposed on the service provider in case poor quality is detected, the lower will be the necessary increase in monitoring cost under outsourcing.

On balance, one cannot say a priori whether outsourcing will yield a social net gain since this will depend on the context. The ownership effect speaks unambigously in favour of outsourcing, and typically one might also expect the competition effect to do so, but the transactions cost effect works in the other direction. In the end, the political decisionmakers will have to evaluate the likely size of these different effects in each specific case before making a decision to organize a public tender for outsourcing.

\footnotetext{
${ }^{27}$ Actually there may be odd cases where the principal does not need to incur additional monitoring costs to secure the benchmark service quality, as I explain in appendix B (see my comments on eq. (B.33)). But in the normal case quality will fall unless monitoring costs are allowed to increase.
} 


\section{Further issues raised by outsourcing}

It should be noted that the model described above does not predict what will actually happen to service quality in case of outsourcing, since this will depend on whether the government purchaser is willing to incur higher monitoring costs. The model assumes that service quality can be observed and verified, albeit only at a cost. Other models of public procurement, including the influential one developed by Hart, Shleifer and Vishny (1997), frequently assume that product quality is not verifiable in a way that can serve as the basis for sanctions enforced by the legal system. In such a setting with incomplete contracting where quality-improving and cost-reducing effort is non-contractible, Hart et al. find that outsourcing of public services will always lead to lower costs, since private owners have an incentive for cost-cutting, whereas service quality may be either higher or lower than under public provision. ${ }^{28}$

The inability to write contracts allowing for all possible contingencies may also mean that outsourcing reduces the government's flexibility to react to unforeseen events. When such events occur, a renogotiation of the contract with the private provider may be needed. If the search and transactions costs of switching to an alternative supplier within the contract period are significant, the resulting bargaining power may enable the current private supplier to extract rents from the government when the contract is renegotiated. This is the "hold-up" problem associated with outsourcing, discussed by Jensen and Stonecash (2005, p. 775). ${ }^{29}$ The risk of hold-up is a cost of outsourcing that must be considered in addition to the factors mentioned earlier.

Another issue is whether the intrinsic motivation of service workers will suffer if service provision is outsourced. Francois (2000) argues that it may well do so. In his model all workers have some public service motivation (PSM), regardless of whether they work for the government or for a private for-profit firm. Thus workers do not care who provides some service that society values, but their PSM means that they care about the level of service provided. For such PSM to motivate a worker's own effort, he must believe that, were he not to make any effort, the level of service would fall. Francois argues that, when the service is publicly provided, workers will expect that service will in fact be reduced if they "shirk", because the public agency has no high-powered incentive to take offsetting actions. But if they work for a private provider, individual workers will expect

\footnotetext{
${ }^{28}$ Interestingly, when the government can write a contract with a public in-house provider that allows the latter to share in any gain from cost-savings, and when the government can also appropriate part of a private provider's gain from cost-cutting (say, through taxation), the model in appendix B implies that the regimes of in-house provision and outsourcing will generate exactly the same outcomes when the cost-sharing parameters are the same (see the last section of appendix B). This result - previously demonstrated by Knabe and Sørensen (2006) - shows that it is the inability to write complete contracts which causes outcomes under in-house provision and outsourcing to differ.

${ }^{29}$ See also Andersson and Jordahl (2011) for a further discussion of incomplete-contracting models of outsourcing.
} 
that their employer will take some action to at least partially offset the loss in service output in case they shirk, for otherwise the employer will lose too much profit. Given these expectations, workers will be less motivated to exert effort under outsourcing than under in-house provision, so outsourcing may lead to lower productivity. This argument is interesting, but it assumes that the stronger inclination towards pro-social behaviour in the public sector reflects the institutional differences between the public and private sectors as such rather than a self-selection of people with a stronger PSM into the public sector. This does not fit with the evidence cited in section 2.2 which suggested that the greater prevalence of PSM in the public sector reflects a selection effect.

\section{What is the evidence on the effects of outsourcing?}

The evidence on the effects of outsourcing has recently been surveyed by Jensen and Stonecash (2005) and Andersson and Jordahl (2011). Here I will make only a few remarks on the main findings in the literature. To evaluate whether outsourcing leads to higher productivity in public service provision, we need data indicating how the ratio between the cost of provision and the quality-adjusted quantity of services delivered is affected by outsourcing. Productivity improves only if the cost per unit of quality-adjusted service goes down. Observing that the total cost of provision goes up or down does not in itself tell us what has happened to productivity. Several years ago, Starr (1988, pp. 6-7) complained that '...most studies comparing public and private organizations lack any evidence about the quality of services, thereby making it difficult to judge whether lower costs result from greater efficiency or reduced service.' Unfortunately this complaint is also relevant for several studies carried out since then, because of lacking data on service quality.

However, a stylized finding from the accumulated evidence is that, when it comes to technical services with small contracting difficulties (e.g., garbage collection, maintenance of roads, vehicles, warehouses and parks, cleaning and housekeeping, student transportation etc.), outsourcing typically leads to cost savings in the order of 5-15 percent (sometimes more, sometimes less) without loss of quality. These findings must be taken with the proviso that the data on quality may be fragile and that the full transactions costs associated with oursourcing may not be included. With these important caveats, it does seem that outsourcing of technical services tends to improve productivity.

When it comes to core welfare services such as child care, home care for the elderly, and the operation of nursing homes, quality requirements are more difficult to specify and write into contracts. In a review of the experience with outsourcing of these three types of welfare service in Denmark and Sweden, Petersen and Hjelmar (2014) find that the evidence regarding effects on costs and quality is mixed. Their main finding is that many studies are characterized by lack of data (especially on quality) and methodological shortcomings that make it very hard to draw strong conclusions on the effects of out- 
sourcing of welfare services to children and the elderly in Scandinavia. ${ }^{30}$ Andersson and Jordahl (2011) review some other studies (from Scandinavia and elsewhere) of service areas with contracting difficulties and likewise conclude that the effects of outsourcing on productivity appears to be mixed.

An interesting issue is whether the efficiency gains from outsourcing - when they materialize - result from a competition effect or from an ownership effect. Many authors have tended to conclude that the competition effect is the more important of the two, but as Andersson and Jordahl (2011) point out, it is very difficult to disentangle the two effects since they are often introduced in tandem. Andersson and Jordahl cite some empirical studies of the UK health care system indicating that competition between public hospitals raises productivity. This is evidence of a competition effect, but whether this is stronger than the ownership effect remains unresolved.

A final contentious issue is whether and how much the observed cost savings from outsourcing reflect a redistribution effect rather than increased efficiency or lower service quality. A redistribution effect occurs if outsourcing leads to lower wages or tougher working conditions for service workers, say, because public sector union contracts no longer apply. Jensen and Stonecash (2005) refer to a number of studies from various countries indicating that such a redistribution effect does sometimes occur. Whether this effect is desirable or not depends on whether one thinks the public or the private sector should set the standard for pay and working conditions. From a general taxpayer perspective it seems desirable to eliminate rents extracted from the public sector. On the other hand, if one feels that the employees working for private service providers are being exploited, say, because they are not unionized, one may deem any redistribution effect to be undesirable. Political opinions on this issue are likely to differ.

\section{Innovation and risk-sharing in public procurement: public-private partnerships}

Public procurers are often keen to specify in great detail the products they want and the way in which services are to be delivered. While this may help to prevent disputes during the contract period, it may also stifle innovation by preventing potential private suppliers from suggesting new ways of producing the service or new types of service satisfying the same needs in a better way. As we have seen, a failure to specify in advance who is going to bear what risks may also require costly negotiations and create hold-up problems after an outsourcing contract has been signed.

In an attempt to address these problems, many OECD governments have experimented for some years with more advanced forms of public procurement, including so-

\footnotetext{
${ }^{30}$ However, in a recent study that does not suffer from the shortcomings mentioned above, Andersen and Jakobsen (2011) analyze hip operations in the Danish health care sector by combining survey and register data. The authors find that, although private health clinics do not achieve better clinical results than public clinics, patient satisfaction is nevertheless higher with private clinics, because they optimize non-clinical factors such as waiting time much more than public clinics.
} 
called public-private partnerships (PPPs). PPPs have mainly been used in infrastructure and construction projects, but they are also finding their way into other areas of public service provision. ${ }^{31}$ Under a PPP, a local or central government agency enters a longterm contract with a private supplier (usually a consortium of firms) for the delivery of some services. The supplier takes responsibility for building the necessary infrastructure and for subsequently maintaining it. Traditionally the private supplier has also provided the finance for the infrastructure investment, but in recent years (part of) the finance for some PPPs has come from governments. PPP contracts often have a length of 20-30 years. Apart from bundling the design, building, finance and operation of the project into one contract, PPP contracts also specify which particular risks must be borne by which partner(s) during the entire term of the contract.

There are two main advantages of PPPs over the traditional form of public procurement. First, because a PPP contract encompasses the construction as well as the subsequent operation of the facility, it can provide better incentives for investments that will reduce future costs or improve future service quality, since the contract can be designed to ensure that those who carry the cost of the investments also receive the future benefits from them. This goes some way towards encouraging innovative investments. Second, the explicit focus on risk-sharing in a PPP helps to identify key risk factors and to allocate the various types of risk to the partners who are in the best position to carry them, thereby reducing the overall cost of risk-taking.

However, there are also drawbacks of PPPs compared to traditional public procurement. In particular, the long contract period in a PPP reduces the flexibility of the public procurer by tying him to a particular supplier for a very long time, and the very detailed and complex structure of many PPP contracts also imply high transactions costs when contracts are negotiated. Private finance for PPP projects may also make them more expensive, because private investors typically have a higher cost of capital than governments who can usually borrow at the risk-free interest rate. ${ }^{32}$

There is a burgeoning literature on PPPs; see Hodge et al. (2010) for a survey. Iossa and Martimort (2014) offer a recent theoretical analysis of the pros and cons relating to PPPs. They find that PPPs are more likely to improve welfare when a better quality of the infrastructure can significantly reduce future costs (including maintenance cost), when infrastructure quality has a great impact on the quality of the service and on service demand, when service quality is verifiable, and when demand for the service is stable and easy to forecast. They argue that this points to the suitability of PPPs in sectors such as transport and water supply, where infrastructure quality is key and demand is relatively stable. To the extent that the conditions just mentioned fail to prevail, PPPs are less

\footnotetext{
${ }^{31}$ For example, in Denmark a recent PPP involves the building and subsequent operation of a complex of nursing homes and accommodations for elderly citizens.

${ }^{32}$ Usually, but not always, as the European sovereign debt crisis sadly taught us!
} 
likely to deliver efficiency gains and may even generate losses compared to simpler forms of procurement.

Against this background it may not be surprising that evaluations of the practical experience with PPPs vary from great praise to strong criticism. Reviewing the evidence on PPPs available at the time, Hodge and Greve (2009, p. 38) concluded: 'The evidence to date is largely based on business case estimates, has an unclear counterfactual and suffers from a host of poor evaluative design features.' Regarding the PPP objective of creating greater value for the taxpayers' money, they continued: '..the most optimistic reading of the evidence thus far is that it is mixed. There is a wide range of both supporting and opposing study results. Much remains to be done to improve the reliability of these findings.' In a more recent Danish survey of the experience with PPPs, Petersen (2013) drew a similar conclusion.

In summary, it seems that public-private partnerships can sometimes be more efficient than traditional forms of public procurement, but like the other policy instruments discussed in this paper, PPPs can also be counterproductive if used in a context for which they are not fit.

\section{Bureaucracy: What drives it? Do we really want to get rid of it?}

As long as anyone can remember, politicians have proclaimed their determination to fight bureaucracy. Rarely does a new government come into office without announcing some new initiative to eliminate unnecessary red tape, to debureaucratize the public sector etc. - or at least not without declaring its intention to take some such future initiative (do you remember Sir Humphrey Appleby?) ${ }^{33}$. Regardless of whom you ask: everyone is against bureaucracy. ${ }^{34}$ Indeed, in an eloquent paper Robert Behn argued that one of the Three Big Questions of public management is the "micromanagement question": "How can public managers break the micromanagement cycle - an excess of procedural rules, which prevents public agencies from producing results, which leads to more procedural rules, which leads to...?' (Behn, 1995, p. 315). And one of the key objectives of the New Public Management was to reduce bureaucracy by shredding rigid process rules in return for greater accountability for results.

So how come that government bureaucracy seems to be ever-expanding if nobody wants it? Is it really true that governments are becoming ever more bureaucratic? And if so, what are the drivers of this process which everyone is apparently against and which

\footnotetext{
${ }^{33}$ If not, you will find some indispensable information here:

http://en.wikipedia.org/wiki/Humphrey_Appleby

${ }^{34}$ If the reader has ever come across a politician who argued in favour of more bureaucracy, kindly send me an e-mail!
} 
seems to reduce prosperity and welfare? In this section I venture a few observations on these issues, realizing that they are clearly too complex and important to be settled in a few pages.

\subsection{Red tape: Is it expanding?}

Everybody seems to know that bureaucracy is increasing, but to my knowledge there isn't a lot of hard evidence on this issue, for how do you measure the extent of bureaucracy and its change over time? One approach to doing so is to count the total number of words in all existing laws and departmental orders and see how this number evolves. Jakobsen and Mortensen (2014) have done so for Denmark. They found that, on average, the total number of words in existing laws grew by about 3 percent per year between 1989 and 2011, whereas the number of words in departmental orders grew by 4 percent annually. These numbers reflect the net increase in the complexity of laws and executive orders, accounting for the expiry or abolition of old laws and regulations as well as for the introduction of new ones and for changes to existing ones.

Taking a somewhat different approach to measuring bureaucracy, Hood, James and Scott (2000) looked at the internal regulation of the UK government, focusing on the socalled secondary overseers of public bodies beyond the courts and the legislature. This involves oversight of bureaucracies by other public agencies operating at arm's length from the direct line of command, the overseers having some sort of official authority over their charges. The secondary regulation is typically a combination of information-gathering, standard setting and attempts to control or modify the behaviour of the regulated bodies. The authors measured the evolution of the number of national-level "regulator" organizations overseeing public-sector bodies, the evolution of their staff size and of the total budgetary cost of running them. They also tried to track the evolution of the total direct costs of complying with the regulations.

The findings of Hood, James and Scott (2000) were remarkable. According to their figures, the number of "regulator" organizations overseeing government grew by over a fifth in the two decades to the mid-1990s. The overall real spending on regulation of government more than doubled over the period, and the total staffing of regulators grew by about 90 percent. This dramatic staff growth took place in a period where the total number of civil servants fell by more than 30 percent and where local authority staff fell by over 20 percent. As the authors note, there was no official policy of increasing regulation of UK government over the twenty years of mostly Conservative government up until 1997. On the contrary, this was a period where the New Public Management slogan of "letting managers manage" was supposed to have led to less regulation of public agencies! Moreover, Hood and his coauthors saw no tendency towards a break with the increasing internal regulation of government during the early years of Tony Blair's New 


\section{Labour government.}

Some years earlier, the Inspectors-General in the US federal government criticized the US Congress and the President for 'a willingness to impose an ever-increasing level of regulatory and reporting requirements on executive agencies and their employees' (Light, 1993, p. 17), and the National Performance Review (1993, p. iii) talked of the need to eliminate 'the structures of overcontrol and micromanagement that now bind the federal government'.

This evidence from three rather different countries on trends that have persisted under governments with quite different ideas on the role of the state suggests that the popular perception of an ever-expanding amount of government bureaucracy is no myth. It seems to be a stark reality. The tough question is: what drives this juggernaut?

\subsection{Red tape: What are the drivers?}

The above quotation from Behn (1995) summarizes a popular answer to this question: rules create the need for more rules in a vicious circle of bureaucracy. Suppose that, for some reason, politicians are unhappy with the performance of some government agency. They therefore enact a new law or ask the relevant ministry to issue a new executive order laying out some rules for how the agency is supposed to do its work. The rules impose new reporting requirements on the agency, drawing some of the effort of its staff away from servicing citizens towards filling forms and writing reports. Perhaps the new rules also reflect an imperfect understanding of the best way to run the agency, thereby constraining the agency's flexibility to find the best solutions to the problems it is supposed to solve. As a result, the performance of the agency declines. Politicians now become more unhappy with the agency. Apparently, the first set of rules was not enough to secure the changes in agency behaviour they demanded. Obviously, politicians reason, there is a need for further rules clarifying how we want the agency staff to do its job. They asked for it! As a result of the next layer of rules, the agency's room for maneuver is further constrained, more paperwork needs to be done, and agency performance takes another dive. Now politicians get really annoyed, so...

In this version of the story of the vicious circle of bureaucracy, it is the politicians who are the villains. If only they could concentrate on defining the broader goals and targets of public policy and leave it to the managers and employees of individual agencies to find

the best technical ways of doing their day-to-day business. Politicians should steer, not row: Let public managers manage!

Sometimes the media are seen as the ultimate villains who start the vicious circle of bureaucracy. Perhaps some individual agency - or some individual staff member in an agency - has made a mistake or has engaged in misconduct that hurts some innocent citizen or group of citizens. As soon as the media and the general public get news of this, 
the scandal is blown up, and some member of the political opposition asks the relevant minister what the government will do to prevent such a thing from ever happening again. The incident may not be very representative (perhaps not at all representative) of what normally happens in the sector or agency of government in question, but the pressure on the minister to do something - or at least to seem to be doing something - is mounting and ultimately becomes irresistible. Perhaps it also offers a welcome opportunity for the minister to take some initiative that will create favourable media coverage. So the minister and his staff issue a new executive order setting out new rules on how agencies or public sector units of the type in question are required to organize their affairs so that things such as the recent scandal can never occur again. The vicious circle of bureaucracy has been set in motion.

The story lines above may have a familiar ring, but they are too simplistic. As Behn (1995, p. 316) points out himself, it is not only the politicians who distrust the ability of public managers and employees to do their jobs properly - the distrust is mutual: people working in the executive branch do not always trust that politicians know best how to run the government (did anyone mention Sir Humphrey again?). This is not a simple problem of mutual bad will reflecting that, by some social misfortune, people with a "wrong" mindset somehow end up in the government and the civil service. Rather, it reflects the uncomfortable fact that the role of politicians cannot in practice be fully separated from the role of civil servants in the way that Woodrow Wilson (1887) hoped. In his vision, politicians would make the decisions about public policy, and career officials would then figure out the most efficient ways to implement these policies, loyally respecting the intentions of the legislature. The problem is that political intentions and decisions are often not stated very clearly, because they are the outcome of an arduous political compromise, or because they reflect a vain hope to avoid unpleasant tradeoffs. Sometimes this leaves considerable room for judgement when the civil servants try to carry out the will of politicians. Even if they try to be loyal, it may not be clear exactly how some policy ought to be implemented. Moreover, sometimes a civil servant may feel that a political decision reflects a lack of understanding of his particular area of administration. If the instructions from policians lack clarity and are felt to reflect ignorance, it is tempting for the civil servant to conclude that he may as well pursue his own agenda when implementing public policy. 'Minister, I admire your idealism, but this simply cannot be done. Never in the history of governments has it been seen to work', Sir Humphrey might say.

As we know, he was sometimes right, but not always. At any rate, even though they are supposed to deal only with the technicalities of administration, civil servants inevitably end up making (and not just implementing) public policy when political decisions leave holes to be filled. Behn (1995) sees this as a basic source of the distrust between politicians and civil servants. Politicians know that their laws leave scope for 
interpretation, so they are tempted to intervene in the administration of policies to make sure that their intentions are carried out. Civil servants resent such intervention, partly because different politicians may seek to move the administration in different directions. Civil servants can react in different ways ('if you distrust us, we will distrust you'): to avoid criticism, they can start working rigidly by the rules and not take any innovative actions, or they can try to get around the rules by various forms of "gaming", as discussed earlier. And so the vicious circle of bureaucracy rolls on.

Identifying the lack of mutual trust as the root of the problem of bureaucracy may be too simplistic, although it is probably part of the true story. In Denmark many public sector employees and their organizations have called for a "Trust Reform" of the public sector, asking to be freed from the many rules and regulations constraining their ability to serve the citizens in a responsive and flexible manner, and asking politicians to trust that adherence to time-honoured professional norms in public administration and service production will suffice to protect citizens from incompetence and misconduct in public agencies.

However, if the source of the mutual distrust is the impossibility of separating decisions on policy from the administration of policy, it may be very hard to break it down. Political leaders with such diverse persuasions as James Madison and Vladimir Lenin did not believe that government can be built only on trust. Nor did Woodrow Wilson, as we noted earlier.

Yet this does not mean that nothing at all can be done to curb bureaucracy, as I will argue in the concluding section. But before then, it is worth asking:

\subsection{Do we really want less bureaucracy?}

The reason for asking is that, if red tape in the government continues to grow regardless of whom we elect to run it, perhaps bureaucracy serves some useful social purpose after all. Max Weber (1947) gave a famous describtion of the positive aspects of bureaucracy. He pointed out that all organizations need some amount of bureaucracy to allocate resources and carry out decisions in an effective manner. He noted that as society becomes more complex, it needs more complex institutions involving more bureaucracy. According to Weber the ideal type bureaucracy is characterized by well-delineated specialized tasks for each staff member and clear rules on decision-making. A well-defined hierarchy is an organizing principle in a bureaucracy. In a well-functioning bureau, the hierarchy of authority is accepted by all employees, and its management is based on written orders. The employees of the bureau are selected on the basis of professional merit to avoid nepotism, and job security is high, often based on life-long employment contracts. Pay increases with promotion in the hierarchy. Weber considered this bureacratic form of organization - characterized by impersonal implementation of impersonal though rational 
rules - to be an effective way of ensuring that the personal interests of individual employees would not hamper the proper functioning of the organization.

In short, Weber considered such an impersonal and rules-bound bureaucracy to be both efficient and fair. In particular, Weberian bureaucracy is well-designed to safeguard the principle of equal treatment of citizens, whether their status in society be high or low. This is an important theme for many other writers on government "bureaucracy". For example, Herbert Kaufman (1977, p. 4) observed that 'One person's 'red tape' may be another's treasured procedural safeguard.'

Hood, James and Scott (2000) interviewed some 80 British civil servants to find out if they saw a need for a significant reduction of the formal regulation of government described earlier. The interviews included both regulators and public managers subject to regulation. Interestingly, several respondents argued that the tendency to move away from Weber-type career service and jobs-for-life employment patterns in the public sector had increased the need for internal regulation through formal rules by undermining the traditional career-based incentives that supported informal controls based on mutual dependence. Some respondents also argued that changes in social norms had necessitated more regulation, as citizens had tended to become more litigious and less compliant consumers with less deference to public-service officials.

Thus, factors like the increasing complexity of society and changing employment patterns and social norms may help to explain some of the increase in "bureaucracy". Jakobsen and Mortensen (2014) also report some findings from Denmark that do not fit well with the simple "vicious-circle-of-bureaucracy" story told earlier. In particular, they found that the policy areas that were initially subject to the greatest amount of rules also experienced the smallest growth in the amount of rules over the period 1989-2011. This suggest that the infamous vicious circle begins to move more slowly as the number of rules goes up: apparently there is a limit to the amount of regulation a given policy area can absorb. The authors also found that new regulation is not mainly driven by "scandals", but rather by issues that appear to be of particular interest to politicians and the general public for more extended periods of time.

A main conclusion in Jakobsen and Mortensen (2014) is that the growth in rules is driven by politicians wanting to make policy, and not by trigger-happy civil servants wishing to increase their power. In a way this is reassuring: we probably would not want it to be the other way around. It is also natural. After all, there are only two basic ways in which politicians can make an impact on society: they can levy taxes and spend the money on persons or activities deemed worthy of public support, or they can create rules regulating the behaviour of individuals and firms. It would be both unrealistic and unreasonable to expect politicians to stop making new rules. But perhaps they could become better at getting rid of old rules that may no longer be needed. I will come back to this theme below. 
In summary, bureaucracy is here to stay, so we had better get used to it. Presumably there is an "optimal" amount of bureaucracy in any society at any given point in time, although I am sure we shall never be in a position to identify (or agree on) the exact location of that optimum. Still, given the pervasive complaints about government red tape, and considering the dramatic growth in rules, regulations and regulating bodies in recent decades, most OECD countries have most likely ended up with more bureaucracy than they need. In the final section I will present a few ideas on what can be done about it.

\section{Conclusions and final reflections on public sector reform}

Demographic trends, mounting government debt burdens and Baumol's cost disease put public budgets under severe pressure, forcing governments to think of ways to increase productivity in public service production. This essay has discussed three tools of public administration and management that have featured prominently in public sector reforms in recent decades, often under the heading of New Public Management (NPM): pay for performance, performance management, and competition in public service provision. I have also discussed some reasons why public administration seems to have become more bureaucratic over time, despite the intention of NPM to move from rules-based to resultsoriented management of public agencies.

It is fair to say that NPM-inspired reforms have generally not lived up to expectations and have often created undesirable side effects. Hence the NPM paradigm has fallen into disgrace in many circles. Yet many key elements of the earlier reforms remain in place throughout the OECD and continue to be debated, and they also continue to pop up in many reform proposals. This explains my choice of focus for this essay. I will start this final section by summarizing my main conclusions. I will then discuss what these conclusions imply for future attempts to reform the public sector.

\subsection{The main conclusions so far}

Pay for performance

Critics of NPM often argue that the introduction of pay for performance (PFP) in the public sector represents a misguided attempt to apply principal-agent theory in a context where it has little or no relevance. But as I showed in section 4.2, principal-agent theory can actually explain why it may make good sense to rely less on (PFP) in the public than in the private sector. Public service production is typically said to be characterized by phenomena such as a relatively high degree of risk-aversion among employees; external influences on public service output beyond the control of the individual service worker; 
difficulties of measuring individual contributions to the output of a team of public service workers; a possible preference for the use of collective rather than individual bonus schemes; the need for public sector workers to perform several different tasks, and the existence of multiple stakeholders who disagree on which tasks should be given priority. The greater the importance of such factors, the weaker should be the link between performance and pay, according to principal-agent theory.

Once it is also recognized that the use of extrinsic incentive schemes like PFP may crowd out the intrinsic motivation of public workers, the case for the use of PFP is further weakened. However, if PFP is designed in a way that supports the norms underlying the intrinsic motivation of public service workers, it may actually strengthen that motivation. In general, neither principal-agent theory nor motivation crowding theory calls for a complete ban on PFP in the public sector. Hence pay for performance is a legitimate tool in the toolbox of public managers, but when considering its use, managers should carefully evaluate how it should be designed and whether it will work as intended in the context of their particular unit.

\section{Performance measurement and benchmarking}

Even if pay is not tied to performance, it may be useful to measure the performance of public agencies so that politicians and citizens can hold them accountable for their actions. Performance measurement (PM) also allows the performances of similar agencies and local jurisdictions to be benchmarked against each other. This may create a healthy yardstick competition and help the less productive organizations to adopt best practices.

But performance measurement (PM) also involves pitfalls. For a variety of reasons, politicians and public sector employees may not actually want performance to be meticulously measured, even if they pay lip service to PM. If the motivation to use the instrument is lacking, PM will be less effective and may create strategic behaviour where agencies pretend to be measuring performance ("gaming") and politicians and top executives pretend to take the measures seriously. Even when the motivation is there, PM may backfire if some important aspects of performance cannot be measured. This will distort the incentives of agencies and may lead to suboptimization ("what doesn't get measured doesn't get done"). A related problem is that PM may induce agencies to focus their efforts on those groups of citizens who are most easy to service or treat ("cream-skimming"). There is also a risk that PM will lead to more bureaucracy and that performance measures will proliferate over time so that public managers and evaluators end up with the DRIP syndrome: data-rich-but-information-poor.

There is no easy way to escape these pitfalls, but there is some evidence that PM can be made to work well (in the sense of helping to improve performance) if it is designed well. Key design elements that seem to increase the likelihood of success are a strong focus on measuring results for citizens, including the quality of the service, a strong link between the various components of the PM system, including information exchange and 
utilization, and avoidance of overly complicated performance measures.

Competition through vouchers and outsourcing

Vouchers giving the holders a right to receive a certain amount of some public service have been used to create competition in several areas of service provision. Voucher schemes are most likely to improve productivity and welfare when the preferences of public service users differ significantly; when service users are well-informed about market conditions; when there are many competing service suppliers, or start-up costs are low so that the market is fully contestable; when service users can easily assess the quality of the service, and when the service is relatively inexpensive and purchased frequently, so users learn by experience. The more these conditions fail to be met, the weaker is the case for a voucher scheme. When used in the education sector, vouchers must be carefully designed to avoid segregation effects.

When the conditions for successful use of vouchers are not met, the government may create competion by outsourcing public service provision via a competitive public tender. Whether this will result in a net social gain depends in large part on the balance between three effects: a competition effect of the public tender that helps to identify the least-cost producer; an ownership effect arising from the stronger incentive for private providers to minimize cost, and a transactions cost effect stemming in part from the costs of organizing public tenders and partly from the need to increase monitoring costs to ensure that private providers do not reduce service quality in order to increae their profit. Under reasonable assumptions, the ownership effect from outsourcing will be unambigously positive for social welfare. The competition effect can also be expected to be positive, whereas the transactions cost effect will be negative. One further aspect is that outsourcing may reduce the flexibility of the government to react to changing circumstances because it is tied to one particular service provider during the contract period. The government may also lose valuable know-how on the details of service production when the service is no longer produced in-house.

Whether outsourcing is a good or a bad idea will thus depend on the context. In each particular case the decision-makers will have to evaluate the relevance and magnitude of the offsetting effects mentioned above.

\section{Bureaucracy}

Under the "big bargain" proposed by the NPM paradigm, public agencies would be freed from rigid process rules in return for greater accountability for their results. This was supposed to reduce bureaucracy by giving agencies much more flexibility to produce good outcomes for citizens. Yet there is evidence that government bureaucracy has grown significantly during the period where NPM-inspired public sector reforms swept through the OECD area. Some of this increase may be explained by changing social norms and employment patterns and the growing complexity of society in general. Another 
important explanation is that politicians and top civil servants could not deliver on their promise to reduce rules-based regulation in return for greater accountability for results. Public agencies were required to deliver ever more detailed reports on their results, but in the end they were not relieved from process rules - on the contrary.

The discussion in section 7.2 suggested two reasons for this. First, since decisions by the legislature often give unclear instructions to civil servants, and since the devil is in the detail, politicians have an incentive to intervene in the work of the executive branch of government to make sure that (their particular interpretation of) the will of politicians is loyally reflected in the actual administration of policy. At the same time, civil servants may feel that politicians lack the insight to intervene competently in their day-to-day business or that a particular intervention lacks legitimacy because it may be challenged by other policians of a different persuasion. Or civil servants may simply want some room of maneuver to pursue their own agenda. The net result is a mutual distrust between politicians and the civil service. This distrust induces politicians to create more rules and regulations to make sure that the civil service implements their policies in the way intended.

Even in the absence of distrust, politicians have a natural incentive to create more rules, since this is one of the most important ways they can make an impact on society, thereby creating a reputation for themselves. Whatever the motive, there is evidence suggesting that it is the politicians rather than the much-derided "bureaucrats" who are the driving force behind the seemingly unstoppable growth in rules and regulations.

\subsection{What are the implications for public sector reform?}

One safe conclusion from all of this is that reforming the public sector successfully is hard! The public sectors of modern welfare states are enormously large, complex and diverse organizations. Policy instruments and management tools that may work well in some parts of the sector may create disasters in other parts, if used indiscriminately without a feel for the specific context. So my first take from the lengthy analysis above is that it invites humility: there is no obvious recipé and no one-size-fits-all set of policy instruments that will guarantee success if you try to reform the public sector with the aim of creating better results for citizens. And this holds even if we could agree on what constitutes "better results for citizens".

Unfortunately, this conclusion is not very helpful for policy makers who would actually like to improve the performance of the public sector. We cannot escape the dilemma that Søren Kierkegaard described so well (cf. the quote at the start of this essay): policy needs to be made, even if we cannot fully anticipate its effects. To illustrate one possible approach to policy advice in the area of public sector reform, I will briefly report the recommendations from the Danish Productivity Commission regarding the main issues 
discussed in this essay. In the present context, the recommendations themselves are less important than the motivation given for them and the caveats attached to them.

Pay for performance. Given the highly compressed wage distribution illustrated in figure 3, and considering that only 8 percent of the public sector wage bill is subject to local wage negotiations, the commission concluded that there is scope for further use of performance-related pay in the Danish public sector. The commission therefore recommended that a larger part of the funds available for public sector pay rises be set aside for negotiation at the level of the individual work place. It also recommended that local public managers be given a key role in the local negotiations over pay. The commission suggested that, in cases where teamwork in the workplace is important, bonuses for good performance could be given to the team and shared equally among its members. The commission acknowledged that in many public sector contexts the scope for PFP will be limited for the reasons given in this essay, but it found that public managers should have the opportunity to use this management tool when they judge that it will promote the goals of the organization.

Performance measurement and benchmarking. The commission proposed to revitalize the NPM idea of replacing process rules and regulations by greater accountability for final results. It stressed the need to focus on final outcomes for citizens and the need to roll back many of the process rules that unduly reduce the flexibility of individual agencies. To promote such a change of regime, the commission proposed an extension of the current rights of individual agencies and local governments to challenge existing process rules imposed by higher-level authorities. Under this procedure an agency may be exempted from a rule or regulation if it can argue persuasively that the rule is unnecessary and constrains its ability to achieve its goals. While stressing that the final decision on process rules must rest with managers and/or politicians, the commission also recommended that public sector employees be given the right to challenge rigid process rules in the local workplace. To promote yardstick competition and learning about best practices, the commission recommended more systematic performance benchmarking. For this purpose it proposed that an independent body with the necessary professional competence be given the task of undertaking performance benchmarking of Danish municipalities and relevant central government agencies. The commission was aware of the pitfalls of performance measurement. It stressed the need to avoid too many goals and targets in performance contracts and suggested that in some cases the current contracts could be replaced by simpler and less formal accountability procedures.

Competition through vouchers and outsourcing. The commission concluded that there is scope for further competition among potential suppliers of public services in Denmark. This conclusion was based inter alia on the observation that only a small share of welfare services is contracted out to private providers. The commission thought that innovation in the production of public services could be stimulated through further cooperation 
with private providers and through further experiments with innovation-friendly forms of procurement, including public-private partnerships. The commission stressed the need to measure and monitor the quality of services delivered and recognized that outsourcing will typically increase the monitoring and transactions costs associated with public service production. The commission also pointed out that the use of voucher schemes under the Danish "Free choice" legislation may sometimes reduce public sector productivity (for the reasons mentioned in section 6.1) and recommended further analysis of this issue. Hence the commission emphasized that, although there is scope for further competition in the Danish public sector, vouchers and outsourcing are not always warranted, and the case for the use of these instruments must be evaluated carefully in each particular context.

The case for a piecemeal approach to reform and the rolling back of bureaucracy

Since the public sector is so large and complex, and since there is so much uncertainty regarding the effects of many proposed policy initiatives, there is a strong case for experimenting on a small scale with new initiatives and policy instruments to see if they work, before one applies them across the board. Such experimentation can take place through pilot schemes. For such schemes to be useful, they must be carefully designed so as to allow a systematic ex-post evaluation of their effects. Of course it is also important to follow up on each scheme: if it seems to work, the new policy should be implemented on a broader scale.

In recent years the Danish government has experimented with two frameworks for pilot schemes intended to roll back excessive bureaucracy. Under the "Free Commune" legislation, Danish municipalities can apply for temporary exemption from specific rules and regulations imposed by the central government if they can demonstrate that this will lead to a better use of resources in local service provision. When the period of exemption expires, the municipality must evaluate the experiment and publish the results of the evaluation. Since the legislation is quite recent, no evaluations have so far been published.

Further, under the "Right-to-Challenge" legislation, an individual public sector unit in the Danish municipalities and regions (counties) can apply for temporary exemption from rules and regulations imposed by the central or local government. Such experiments are currently allowed until 2015.

As an illustration of the difficulty of rolling back bureaucracy, the Danish central government has rejected a large part of the applications submitted under the Free Commune and Right-to-Challenge programs, often with the motivation that an exemption from a certain rule "goes against government policy". The Danish Productivity Commission has recommended a more liberal central government attitude towards the pilot schemes proposed under the two programs. It has also recommended that the Right-to-Challenge be extended to all public sector units, including those of the central government. Further, the commission recommended that all pilot schemes under the two programs be systematically evaluated by an independent body, that the Danish parliament be obliged 
to follow up on all evaluations and to consider a general (i.e., nationwide) abolition or modification of a particular rule whenever the evaluation of a pilot scheme suggests that the rule is unnecessary or harmful. Finally, the commission has proposed that parliament as well as local governments systematically review all major internal regulations of the central and local governments at regular intervals to evaluate whether existing rules have outlived their purpose and may be scrapped.

It is not clear whether such a pragmatic and piecemeal approach to debureaucratization and public sector reform will work. But since previous reform efforts have met with limited success, it seems worthwhile to experiment with new approaches. In any case: the debate on public sector reform continues! 


\section{APPENDIX A \\ SOME BASIC PRINCIPAL-AGENT MODELS}

This appendix documents the findings from the principal-agent models reported in section 5.2. As mentioned there, the analysis is much inspired by Dixit (2002), but we also present some new results.

\section{The basic principal-agent model with moral hazard}

In this model there is one principal and one agent. The agent exerts effort $e$ which results in a stochastic outcome $x$ given by

$$
x=e+\varepsilon, \quad \varepsilon \sim N\left(0, \sigma^{2}\right),
$$

where $\varepsilon \sim N\left(0, \sigma^{2}\right)$ signifies that the noise variable $\varepsilon$ is normally distributed with mean zero and variance $\sigma^{2}$. The realized utility of the agent is

$$
u=u(y-C), \quad u^{\prime}>0, \quad u^{\prime \prime}<0,
$$

where $y$ is the agent's income, and $C$ is his cost of effort. The principal can observe the outcome of the agent's effort and pays him according to the following linear reward scheme, where $k$ and $m$ are parameters chosen by the principal:

$$
y=k+m x .
$$

The agent's marginal cost of effort is increasing, as reflected in the quadratic cost function

$$
C=\frac{c e^{2}}{2}, \quad c>0, \quad c \text { constant. }
$$

Since $\varepsilon$ is normally distributed and $C$ is non-stochastic, it follows from (A.1) and (A.3) that $y-C$ is also normally distributed. Assuming that the utility function $u(\cdot)$ displays constant absolute risk aversion, maximization of the agent's expected utility is therefore equivalent to maximizing the following utility function where $\mathrm{E}[\cdot]$ indicates a mean and $\operatorname{var}[\cdot]$ indicates a variance: ${ }^{35}$

$$
U=\mathrm{E}[y-C]-\frac{\rho}{2} \operatorname{var}[y-C], \quad \rho>0, \quad \rho \text { constant. }
$$

The parameter $\rho$ is the agent's coefficient of absolute risk aversion. From (A.1), (A.3) and (A.4) we find the mean value of the agent's net payoff to be

$$
\mathrm{E}[y-C]=k+m e-\frac{c e^{2}}{2}
$$

\footnotetext{
${ }^{35}$ This follows from the general result that an agent's expected utility may be expressed as a linear function of the mean and the variance of the utility-generating variable when the latter follows a normal distribution and the agent has constant absolute risk aversion. See, e.g., Silberberg and Suen (2001, pp. 407-408) for a proof of this result.
} 
while the variance of his net payoff is

$$
\operatorname{var}[y-C]=\mathrm{E}\left[(k+m(e+\varepsilon)-k-m e)^{2}\right]=\mathrm{E}\left[(m \varepsilon)^{2}\right]=m^{2} \sigma^{2} .
$$

Inserting (A.6) and (A.7) in (A.5), we may write the (monotonic transformation of the) agent's expected utility as

$$
U=k+m e-\frac{c e^{2}}{2}-\frac{\rho m^{2} \sigma^{2}}{2} .
$$

To maximize his expected utility, the agent must meet the first-order condition $d U / d e=$ 0. From (A.8) this implies that his optimal effort is given by

$$
e=\frac{m}{c} \text {. }
$$

The principal's realized utility level is

$$
v=v(x-y), \quad v^{\prime}>0, \quad v^{\prime \prime}<0,
$$

where the utility function $v(\cdot)$ displays constant absolute risk aversion with a coefficient of risk aversion equal to $R$. Eqs. (A.1) and (A.3) imply that the principal's net payoff $x-y$ follows a normal distribution. Maximization of the principal's expected utility is thus equivalent to maximizing the utility function

$$
V=\mathrm{E}[x-y]-\frac{R}{2} \operatorname{var}[x-y], \quad R>0, \quad R \text { constant }
$$

where (A.1) and (A.3) yield

$$
\mathrm{E}[x-y]=(1-m) e-k,
$$

and

$$
\operatorname{var}[x-y]=(1-m)^{2} \sigma^{2} .
$$

Substituting (A.9), (A.12) and (A.13) in (A.11), we may write the principal's expected utility as

$$
V=\frac{(1-m) m}{c}-k-\frac{R \sigma^{2}(1-m)^{2}}{2}
$$

The principal maximizes $V$ with respect to the pay scheme parameters $k$ and $m$, subject to the participation constraint that he must secure the agent an expected utility level at least as high as the exogenous (expected) utility $u^{*}$ obtainable in the agent's best available outside option. Inserting (A.9) in (A.8), we may write this participation constraint as

$$
k+\frac{m^{2}}{2 c}-\frac{\rho m^{2} \sigma^{2}}{2} \geq u^{*} .
$$

In the principal's optimum the participation constraint will be binding, since otherwise he could reduce $k$, thereby increasing his utility without inducing the agent to exercise the 
outside option. From (A.14) and (A.15) we then get the principal's Lagrangian, where $\lambda$ is the Lagrange multiplier associated with the participation constraint:

$$
L=\frac{(1-m) m}{c}-k-\frac{R \sigma^{2}(1-m)^{2}}{2}+\lambda\left(k+\frac{m^{2}}{2 c}-\frac{\rho m^{2} \sigma^{2}}{2}-u^{*}\right) .
$$

The principal's first-order conditions are

$$
\begin{gathered}
\partial L / \partial k=0 \quad \Longrightarrow \quad \lambda=1, \\
\partial L / \partial m=0 \Longrightarrow \frac{1-2 m}{c}+R \sigma^{2}(1-m)+\lambda\left(\frac{m}{c}-\rho \sigma^{2} m\right)=0 .
\end{gathered}
$$

The optimal value of $m$ stated in eq. (5) in section 5.2 follows from (A.17) and (A.18). Once $m$ is found, we can derive $k$ from (A.15), given that the participation constraint must be satisfied with equality in the principal's optimum.

\section{Multiple agents}

We now abstract from stochastic influences on output. Instead we assume that there are two agents, 1 and 2, whose efforts $e_{1}$ and $e_{2}$ contribute equally to total service output:

$$
x=e_{1}+e_{2} .
$$

Total output is still fully observable, but each agent's contribution to total output can only be measured with a stochastic, symmetric normally distributed error, $\varepsilon$. Hence the measured outputs of the two agents (indicated by hat superscripts) are

$$
\widehat{e}_{1}=e_{1}+\varepsilon, \quad \widehat{e}_{2}=e_{2}-\varepsilon, \quad \varepsilon \sim N\left(0, \sigma^{2}\right)
$$

The individual agent is paid according to his measured performance, so the income of agent $i\left(y_{i}\right)$ is

$$
y_{i}=k+m \widehat{e}_{i}, \quad i=1,2 .
$$

For both agents the cost of effort is given by (A.4), and they both have the utility function (A.2) with constant absolute risk aversion. Hence they both have an expected utility function of the form (A.5), where (A.20) and (A.21) imply that

$$
\mathrm{E}\left[y_{i}-C_{i}\right]=k+m e_{i}-\frac{c e_{i}^{2}}{2}, \quad \operatorname{var}\left[y_{i}-C_{i}\right]=m^{2} \sigma^{2}, \quad i=1,2 .
$$

Inserting (A.22) in (A.5) and maximizing each agent's expected utility with respect to his effort, we get

$$
e_{i}=e=\frac{m}{c} .
$$

Thus both agents will exert the same effort level $e$ because they both face the same pay scheme. 
Since total output is deterministic, the principal obtains the safe payoff

$$
\begin{aligned}
V & =x-y_{1}-y_{2} \\
& =e_{1}+e_{2}-2 k-m\left(e_{1}+e_{2}\right) \\
& =\frac{2 m}{c}(1-m)-2 k,
\end{aligned}
$$

where we have used (A.21) and (A.23) to arrive at the bottom line in (A.24). The participation constraint requires that the individual agent be offered an expected utility at least equal to his outside option $u^{*}$. From (A.5), (A.22) and (A.23) it follows that the participation constraint takes exactly the same form as (A.15). The principal will therefore wish to maximize (A.24) with respect to $k$ and $m$, subject to (A.15). The first-order conditions for the solution to this problem yield eq. (9) in section 5.2.

Teamwork with a collective bonus scheme

Consider next a situation with a team of $n$ agents whose efforts contribute equally to an output which is subject to a stochastic influence. Specifically, total output is

$$
x=\sum_{i=1}^{n} e_{i}+\varepsilon, \quad \varepsilon \sim N\left(0, \sigma^{2}\right) .
$$

Total output is still fully observable by the principal, but he cannot pay the individual agent according to the latter's contribution to total output, either because the individual contribution is unobservable or because an egalitarian norm dictates that all agents be paid the same wage. Instead, the principal pays each agent a wage consisting of a fixed component plus a bonus which is proportional to the average output per team member $(x / n)$ :

$$
y_{i}=y=k+m \frac{x}{n} .
$$

The individual agent's cost of effort and his expected utility are still given by (A.4) and (A.5), respectively, but (A.26) implies that the mean and the variance of his net payoff are

$$
\mathrm{E}\left[y_{i}-C_{i}\right]=k+\frac{m}{n} e_{i}-\frac{c e_{i}^{2}}{2}, \quad \operatorname{var}\left[y_{i}-C_{i}\right]=\left(\frac{m}{n}\right)^{2} \sigma^{2}, \quad \forall i .
$$

Inserting (A.27) into (A.5) and maximizing with respect to $e_{i}$, we find that all agents will want to exert the same amount of effort given by

$$
e_{i}=e=\frac{m}{n c} \text {. }
$$

The principal's net payoff is $x-n y$. From (A.26) and (A.28) we obtain the mean and the variance of this payoff:

$$
\begin{gathered}
\mathrm{E}[x-n y]=\frac{(1-m) m}{c}-n k \\
\operatorname{var}[x-n y]=(1-m)^{2} \sigma^{2} .
\end{gathered}
$$


With constant absolute risk aversion, it follows from (A.29) and (A.30) that the principal's expected utility is

$$
\begin{aligned}
V & =\mathrm{E}[x-n y]-\frac{R}{2} \operatorname{var}[x-n y] \\
& =\frac{(1-m) m}{c}-n k-\frac{R(1-m)^{2} \sigma^{2}}{2} .
\end{aligned}
$$

Using (A.4), (A.5), (A.27) and (A.28), we may write the representative team member's participation constraint as

$$
\begin{gathered}
U=\mathrm{E}[y-C]-\frac{\rho}{2} \operatorname{var}[y-C] \geq u^{*} \Longrightarrow \\
k+\frac{m^{2}}{n c}\left(1-\frac{1}{2 n}\right)-\frac{\rho \sigma^{2} m^{2}}{2 n^{2}} \geq u^{*} .
\end{gathered}
$$

The principal maximizes (A.31) with respect to $k$ and $m$, subject to (A.32). From the first-order conditions for a maximum we obtain eq. (12) in section 5.2.

\section{Multiple tasks}

Let us return to the case with only one agent and one principal, but let us assume that the agent spends efforts $e_{1}$ and $e_{2}$ on two different tasks generating stochastic outputs $x_{1}$ and $x_{2}$. For simplicity, we assume that the stochastic components in the two outputs have the same variance, $\sigma^{2}$, and that they follow independent normal distributions:

$$
\begin{gathered}
x_{1}=e_{1}+\varepsilon_{1}, \quad \varepsilon_{1} \sim N\left(0, \sigma^{2}\right), \\
x_{2}=e_{2}+\varepsilon_{2}, \quad \varepsilon_{2} \sim N\left(0, \sigma^{2}\right), \quad \mathrm{E}\left[\varepsilon_{1} \varepsilon_{2}\right]=0 .
\end{gathered}
$$

The agent's performance pay is a linear function of the outputs resulting from his efforts, so his income is

$$
\begin{aligned}
y & =k+m_{1} x_{1}+m_{2} x_{2} \\
& =k+m_{1}\left(e_{1}+\varepsilon_{1}\right)+m_{2}\left(e_{2}+\varepsilon_{2}\right) .
\end{aligned}
$$

Following Dixit (2002, p. 705), we assume that the agent's total cost of effort is

$$
C=\frac{c\left(e_{1}^{2}+e_{2}^{2}+2 \alpha e_{1} e_{2}\right)}{2} .
$$

Hence the marginal costs of effort in the two tasks are

$$
\partial C / \partial e_{1}=c\left(e_{1}+\alpha e_{2}\right), \quad \partial C / \partial e_{2}=c\left(e_{2}+\alpha e_{1}\right) .
$$

If $\alpha>0$, the marginal cost of effort in one task increases with the amount of effort spent on the other task. In this case the tasks are said to be substitutes. Conversely, if $\alpha<0$, the two tasks are said to be complements, since the marginal cost of effort in one task will then decline as the agent spends more effort on the other task. 
The agent's expected utility is still given by (A.5), so by using (A.33) through (A.35) we find his expected utility to be

$$
\begin{aligned}
U & =\mathrm{E}[y-C]-\frac{\rho}{2} \operatorname{var}[y-C] \\
& =k+m_{1} e_{1}+m_{2} e_{2}-\frac{c\left(e_{1}^{2}+e_{2}^{2}+2 \alpha e_{1} e_{2}\right)}{2}-\frac{\rho \sigma^{2}\left(m_{1}^{2}+m_{2}^{2}\right)}{2}
\end{aligned}
$$

By maximizing (A.37) with respect to $e_{1}$ and $e_{2}$, we can use the first-order conditions to find the agent's optimal efforts:

$$
e_{1}=\frac{m_{1}-\alpha m_{2}}{c\left(1-\alpha^{2}\right)}, \quad e_{2}=\frac{m_{2}-\alpha m_{1}}{c\left(1-\alpha^{2}\right)} .
$$

The principal cares about the total output produced by the agent, so his realized net payoff is $x_{1}+x_{2}-y$. Using (A.33) and (A.34) and maintaining the assumption of constant absolute risk aversion, we can write the principal's expected utility as

$$
\begin{aligned}
V & =\mathrm{E}\left[x_{1}+x_{2}-y\right]-\frac{R}{2} \operatorname{var}\left[x_{1}+x_{2}-y\right] \\
& =\left(1-m_{1}\right) e_{1}+\left(1-m_{2}\right) e_{2}-k-\frac{R \sigma^{2}\left[\left(1-m_{1}\right)^{2}+\left(1-m_{2}\right)^{2}\right]}{2} .
\end{aligned}
$$

With an outside option $u^{*}$, it follows from (A.37) that the agent's participation constraint is

$$
U=k+m_{1} e_{1}+m_{2} e_{2}-\frac{c\left(e_{1}^{2}+e_{2}^{2}+2 \alpha e_{1} e_{2}\right)}{2}-\frac{\rho \sigma^{2}\left(m_{1}^{2}+m_{2}^{2}\right)}{2} \geq u^{*} .
$$

The principal maximizes (A.39) subject to (A.40), accounting for the effects of his choice of $m_{1}$ and $m_{2}$ on the agent's efforts (cf. (A.38)). The principal's first-order conditions for the optimal choice of $k, m_{1}$ and $m_{2}$ can be shown to imply the following relationships:

$$
\begin{aligned}
& R \sigma^{2}\left(1-m_{1}\right)-\rho \sigma^{2} m_{1}+\frac{\partial e_{1}}{\partial m_{1}}+\frac{\partial e_{2}}{\partial m_{1}}-c e_{1}\left(\frac{\partial e_{1}}{\partial m_{1}}+\alpha \frac{\partial e_{2}}{\partial m_{1}}\right)-c e_{2}\left(\frac{\partial e_{2}}{\partial m_{1}}+\alpha \frac{\partial e_{1}}{\partial m_{1}}\right)=0, \\
& R \sigma^{2}\left(1-m_{2}\right)-\rho \sigma^{2} m_{2}+\frac{\partial e_{1}}{\partial m_{2}}+\frac{\partial e_{2}}{\partial m_{2}}-c e_{1}\left(\frac{\partial e_{1}}{\partial m_{2}}+\alpha \frac{\partial e_{2}}{\partial m_{2}}\right)-c e_{2}\left(\frac{\partial e_{2}}{\partial m_{2}}+\alpha \frac{\partial e_{1}}{\partial m_{2}}\right)=0 .
\end{aligned}
$$

From (A.38) we have

$$
\frac{\partial e_{1}}{\partial m_{1}}=\frac{\partial e_{2}}{\partial m_{2}}=\frac{1}{c\left(1-\alpha^{2}\right)}, \quad \frac{\partial e_{2}}{\partial m_{1}}=\frac{\partial e_{1}}{\partial m_{2}}=\frac{-\alpha}{c\left(1-\alpha^{2}\right)} .
$$

Inserting (A.43) in (A.41) and (A.42) and using the fact that $\left(1-\alpha^{2}\right)=(1+\alpha)(1-\alpha)$, we obtain

$$
\begin{aligned}
& R \sigma^{2}\left(1-m_{1}\right)-\rho \sigma^{2} m_{1}+\frac{1}{c(1+\alpha)}\left(1+\frac{\alpha m_{2}-m_{1}}{1-\alpha}\right)=0 \\
& R \sigma^{2}\left(1-m_{2}\right)-\rho \sigma^{2} m_{2}+\frac{1}{c(1+\alpha)}\left(1+\frac{\alpha m_{1}-m_{2}}{1-\alpha}\right)=0 .
\end{aligned}
$$


Solving (A.44) and (A.45) for $m_{1}$ and $m_{2}$, we find that $m_{1}=m_{2}=m$, where $m$ is given by eq. (16) in section 5.2.

\section{Multiple principals and tasks}

Consider finally a scenario where one agent carries out two tasks for two different principals, $A$ and $B$. The two outputs $x_{1}$ and $x_{2}$ produced by the agent are still given by (A.33), but now his total income $y$ consists of the sum of the incomes $y^{A}$ and $y^{B}$ received from the two principals. Both principals pays the agent according to a linear pay scheme, but the coefficients in the reward schemes differ because the principals have different preferences for the two outputs. Hence we have

$$
\begin{gathered}
y=y^{A}+y^{B}, \\
y^{A}=k^{A}+m_{1}^{A} x_{1}+m_{2}^{A} x_{2}, \\
y^{B}=k^{B}+m_{1}^{B} x_{1}+m_{2}^{B} x_{2} .
\end{gathered}
$$

The two tasks performed by the agent are neither substitutes nor complements, i.e., the parameter $\alpha$ in (A.35) is zero, so the agent's cost of effort is

$$
C=\frac{c\left(e_{1}^{2}+e_{2}^{2}\right)}{2} .
$$

The agent's expected utility is still described by (A.5). Using this along with (A.33) and (A.46) through (A.49), we thus find the agent's expected utility to be

$$
\begin{gathered}
U=\mathrm{E}[y-C]-\frac{\rho}{2} \operatorname{var}[y-C] \Longrightarrow \\
U=k^{A}+k^{B}+\left(m_{1}^{A}+m_{1}^{B}\right) e_{1}+\left(m_{2}^{A}+m_{2}^{B}\right) e_{2}-\frac{c\left(e_{1}^{2}+e_{2}^{2}\right)}{2} \\
-\frac{\rho \sigma^{2}\left[\left(m_{1}^{A}+m_{1}^{B}\right)^{2}+\left(m_{2}^{A}+m_{2}^{B}\right)^{2}\right]}{2} .
\end{gathered}
$$

From the first-order conditions $\partial U / \partial e_{1}=0$ and $\partial U / \partial e_{2}=0$ we obtain the agent's optimal efforts:

$$
e_{1}=\frac{m_{1}^{A}+m_{1}^{B}}{c}, \quad e_{2}=\frac{m_{2}^{A}+m_{2}^{B}}{c} .
$$

Substituting (A.51) in (A.50), we can write the agent's participation constraint as

$$
k^{A}+k^{B}+\frac{\left(m_{1}^{A}+m_{1}^{B}\right)^{2}}{2 c}+\frac{\left(m_{2}^{A}+m_{2}^{B}\right)^{2}}{2 c}-\frac{\rho \sigma^{2}\left[\left(m_{1}^{A}+m_{1}^{B}\right)^{2}+\left(m_{2}^{A}+m_{2}^{B}\right)^{2}\right]}{2} \geq u^{*} \text {. }
$$

Principal $A$ cares only about the output $x_{1}$ from task 1 , so from (A.33), (A.47) and (A.51) we find his expected utility to be

$$
\begin{aligned}
V & =\mathrm{E}\left[x_{1}-y^{A}\right]-\frac{R}{2} \operatorname{var}\left[x_{1}-y^{A}\right] \\
& =\left(1-m_{1}^{A}\right) e_{1}-m_{2}^{A} e_{2}-k^{A}-\frac{R \sigma^{2}\left[\left(1-m_{1}^{A}\right)^{2}+\left(m_{2}^{A}\right)^{2}\right]}{2} \Longrightarrow
\end{aligned}
$$




$$
V=\left(1-m_{1}^{A}\right)\left(\frac{m_{1}^{A}+m_{1}^{B}}{c}\right)-m_{2}^{A}\left(\frac{m_{2}^{A}+m_{2}^{B}}{c}\right)-k^{A}-\frac{R \sigma^{2}\left[\left(1-m_{1}^{A}\right)^{2}+\left(m_{2}^{A}\right)^{2}\right]}{2} .
$$

The principals play Nash against each other. Thus principal $A$ maximizes (A.53) with respect to $k^{A}, m_{1}^{A}$ and $m_{2}^{A}$ subject to (A.52), taking $k^{B}, m_{1}^{B}$ and $m_{2}^{B}$ as given. The first-order conditions for the solution to this problem can be shown to imply that

$$
m_{1}^{A}=\frac{1+c \sigma^{2}\left(R-\rho m_{1}^{B}\right)}{1+c \sigma^{2}(\rho+R)}, \quad m_{2}^{A}=\frac{-c \rho \sigma^{2} m_{2}^{B}}{1+c \sigma^{2}(\rho+R)} .
$$

In contrast to principal $A$, principal $B$ cares only about the output $x_{2}$, so his realized net payoff is $x_{2}-y^{B}$. Hence $B$ solves a problem symmetric to that of $A$, yielding

$$
m_{1}^{B}=\frac{-c \rho \sigma^{2} m_{1}^{A}}{1+c \sigma^{2}(\rho+R)}, \quad m_{2}^{B}=\frac{1+c \sigma^{2}\left(R-\rho m_{2}^{A}\right)}{1+c \sigma^{2}(\rho+R)} .
$$

From (A.54) and (A.55) one finds

$$
\begin{aligned}
& m_{1}^{A}=\frac{\left(1+c \sigma^{2} R\right)\left[1+c \sigma^{2}(\rho+R)\right]}{\left[1+c \sigma^{2}(\rho+R)\right]^{2}-\left(c \rho \sigma^{2}\right)^{2}}, \\
& m_{1}^{B}=\frac{-c \sigma^{2} \rho\left(1+c \sigma^{2} R\right)}{\left[1+c \sigma^{2}(\rho+R)\right]^{2}-\left(c \rho \sigma^{2}\right)^{2}} .
\end{aligned}
$$

According to (A.56) and (A.57), the agent's total bonus from producing an extra unit of $x_{1}$ is

$$
m_{1} \equiv m_{1}^{A}+m_{1}^{B}=\frac{\left(1+c \sigma^{2} R\right)^{2}}{D}, \quad D \equiv\left[1+c \sigma^{2}(\rho+R)\right]^{2}-\left(c \rho \sigma^{2}\right)^{2} .
$$

Calculating the denominator in (A.58), we obtain

$$
D=\left(1+c \sigma^{2} R\right)\left(1+c \sigma^{2} R+2 c \sigma^{2} \rho\right)
$$

We may now substitute (A.59) into (A.58) to get

$$
m_{1}=\frac{1+c \sigma^{2} R}{1+c \sigma^{2}(\rho+R)+c \sigma^{2} \rho},
$$

which is identical to eq. (19) in section 5.2. Because of the symmetry properties of the model, $m_{2} \equiv m_{2}^{A}+m_{2}^{B}$ is found from (A.56) and (A.57) to be identical to the expression in (A.60). 


\section{APPENDIX B \\ A SIMPLE MODEL OF OUTSOURCING}

This appendix describes the model of outsourcing of public service provision discussed in section $6.2{ }^{36}$ We start by analyzing the situation with in-house public production of the service considered. Then we compare that situation to a scenario where the service is produced by a private firm paid by the government.

\section{In-house provision}

The public service worker

The government principal pays an agent (a public sector worker or a group of identical workers) to provide some service to citizens. The (quality-adjusted) amount of service output $x$ is a deterministic linear function of the effort $e$ exerted by the agent:

$$
x=e
$$

The agent's cost of effort $(C)$ is

$$
C=\frac{c e^{2}}{2}, \quad c>0
$$

and his level of utility $(u)$ is a concave function of his net payoff, $z$ :

$$
u=u(z), \quad u^{\prime}>0, \quad u^{\prime \prime}<0
$$

The principal does not observe the amount of service output on a continuous basis, but with some frequency $p(0<p<1)$ per period he undertakes an inspection enabling him to verify the amount of service delivered to citizens. If the observed actual service $x$ falls short of some exogenous benchmark level $x^{*}$, the agent (the service worker) is penalized by a fine which is proportional to the service shortfall. Symmetrically, if the actual service is found to exceed the benchmark level, the service worker is rewarded by a proportional bonus. Thus we have

$$
Z=P\left(x^{*}-x\right), \quad P>c x^{*}
$$

where $Z$ is the total fine, and $-Z$ is the bonus if $x>x^{*}$. The parameter $P$ is the exogenous rate of penalty or reward which is assumed to exceed the marginal cost of effort at the benchmark service level $x^{*}$ (note from (B.1) and (B.2) that this marginal effort cost is $c x^{*}$ ). In addition to the fine or bonus, the agent's income includes a fixed wage component, $w$. The agent's total payoff $z$ is his income minus his cost of effort. Hence

$$
z=w-C-Z \quad \text { with probability } p, \quad z=w-C \quad \text { with probability } 1-p .
$$

\footnotetext{
${ }^{36}$ The model is a modified version of the one set up in Knabe and Sørensen (2006).
} 
From (B.1) through (B.5) it follows that the agent's expected utility $U$ is

$$
U=p u\left(w-\frac{c e^{2}}{2}-P\left(x^{*}-e\right)\right)+(1-p) u\left(w-\frac{c e^{2}}{2}\right) .
$$

The agent chooses his effort so as to maximize his expected utility. According to (B.6) the necessary and sufficient conditions for the solution to this problem are

$$
\begin{gathered}
\partial U / \partial e=0 \Longrightarrow \\
p u^{\prime}\left(w-\frac{c e^{2}}{2}-P\left(x^{*}-e\right)\right)(P-c e)-(1-p) u^{\prime}\left(w-\frac{c e^{2}}{2}\right) c e=0 \\
\partial^{2} U /(\partial e)^{2}<0 .
\end{gathered}
$$

The first-order condition (B.7) can be written as an implicit function of the form $f(e, p)=$ 0 , where

$$
\frac{d e}{d p}=-\frac{\partial f / d p}{d f / d e}=-\frac{\partial^{2} U / \partial e \partial p}{\partial^{2} U /(\partial e)^{2}}
$$

The second-order condition (B.8) implies that the denominator in (B.9) is negative. From the expression on the left-hand side of (B.7) we find the numerator to be

$$
\frac{\partial^{2} U}{\partial e \partial p}=u^{\prime}\left(w-\frac{c e^{2}}{2}-P\left(x^{*}-e\right)\right)(P-c e)+u^{\prime}\left(w-\frac{c e^{2}}{2}\right) c e .
$$

In an economically meaningful equilibrium with positive marginal utility and positive effort (i.e., $u^{\prime}(\cdot)>0$ and $e>0$ ), it follows from (B.7) that $P>c e$ in the agent's optimum (since $0<p<1$ ). According to (B.10) we can therefore be sure that $\partial^{2} U / \partial e \partial p>0$. From (B.8) and (B.9) we then get $d e / d p>0$. In other words, the agent's optimal effort is a monotonously increasing function of the monitoring intensity $p$, that is:

$$
e=e(p), \quad e^{\prime}>0
$$

By choosing an appropriate value of $p$, the principal can therefore ensure any desired service level $x=e$.

\section{Government expenditure under in-house provision}

Suppose the principal chooses the monitoring intensity $p^{*}$ that will generate the benchmark service level $x^{*}$, i.e., the value of $p$ satisfying $x^{*}=e^{*}=e\left(p^{*}\right)$. The first-order condition (B.7) then simplifies to

$$
\begin{gathered}
p^{*}\left(P-c x^{*}\right)-\left(1-p^{*}\right) c x^{*}=0 \quad \Longleftrightarrow \\
p^{*}=\frac{c x^{*}}{P} .
\end{gathered}
$$

For the purpose of comparing to a scenario with outsourcing, we want to identify the public expenditure necessary to generate the benchmark service level $x^{*}$ under in-house 
provision. We assume that, in addition to the wage paid to the service worker, the government must also pay a fixed overhead cost $F$ to be able to able to deliver the public service. Moreover, we assume that the government incurs a constant marginal cost $a$ whenever it increases the monitoring intensity $p$. Hence the government's total cost $G$ of in-house provision of the benchmark service level is

$$
G=F+w+a p^{*}
$$

Note that the government budget in (B.13) does not include any revenue from fines or expenses on bonuses since these will be zero when the benchmark service level is attained.

To attract a public sector worker, the government must pay him a wage that ensures him an expected utility at least as high as the utility $u\left(z^{*}\right)$ he would get from the (exogenous) payoff $z^{*}$ he could obtain in the private labour market. When $p=p^{*}$, we have $e=x^{*}$ and $Z=0$, so the worker's utility from public employment will be $u(w-C)$ whether he is inspected or not. Using (B.2), we can then easily calculate the minimum wage the government must offer to attract the service worker (the wage ensuring that $\left.w-C=z^{*}\right)$ :

$$
w=z^{*}+\frac{c\left(x^{*}\right)^{2}}{2}
$$

Inserting (B.12) and (B.14) into (B.13), we get

$$
G=F+z^{*}+\frac{c\left(x^{*}\right)^{2}}{2}+\frac{a c x^{*}}{P}
$$

Below we will compare the spending level in (B.15) to that emerging under outsourcing.

\section{Outsourcing}

The private entrepreneur

Under in-house provision the public service worker has no incentive to exert effort to reduce the fixed cost of service provision since this does not affect his pay. But when service delivery is outsourced to a private entrepreneur, the entrepreneur will have such an incentive since the cost saving will increase his profit. We therefore assume that, in addition to the effort $e_{1}$ spent on servicing the citizens, the entrepreneur may also exert an effort $e_{2}$ on activities that will reduce his overhead cost $F^{\pi}$ of service production. Specifically, we assume that this overhead cost varies negatively and (within the relevant range of variation) linearly with $e_{2}$ :

$$
F^{\pi}=F_{o}-b e_{2}, \quad F_{o}>0, \quad b>0 .
$$

Parallel to eq. (A.35) in appendix A, we assume that the marginal cost of effort exerted on one task may affect the marginal cost of performing the other task so that the entrepreneur's total cost of effort is

$$
C=\frac{c\left(e_{1}^{2}+e_{2}^{2}+2 \alpha e_{1} e_{2}\right)}{2} .
$$


As in appendix A, the parameter $\alpha$ may be either positive or negative, depending on whether the two tasks are substitutes or complements.

The level of service provided to citizens is now $x=e_{1}$. The government principal monitors the performance of the entrepreneur with the frequency $p$ and imposes a fine or pays a bonus in accordance with (B.4) if the observed service level deviates from the benchmark level $x^{*}$. Hence the entrepreneur's payoffs in the two possible states are

$$
\begin{gathered}
z^{\pi}=w^{\pi}-F^{\pi}-C-P\left(x^{*}-e_{1}\right) \quad \text { with probability } p, \\
z^{\pi}=w^{\pi}-F^{\pi}-C \quad \text { with probability } 1-p,
\end{gathered}
$$

where $w^{\pi}$ is a fixed payment and $P$ is the rate of penalty or bonus, as in the case of in-house provision. The entrepreneur's realized utility is $u\left(z^{\pi}\right)$, so from (B.16) through (B.18) we find his expected utility $\left(U^{\pi}\right)$ to be

$$
\begin{aligned}
U^{\pi}= & p u\left(w^{\pi}-F_{o}+b e_{2}-\frac{c\left(e_{1}^{2}+e_{2}^{2}+2 \alpha e_{1} e_{2}\right)}{2}-P\left(x^{*}-e_{1}\right)\right) \\
& +(1-p) u\left(w^{\pi}-F_{o}+b e_{2}-\frac{c\left(e_{1}^{2}+e_{2}^{2}+2 \alpha e_{1} e_{2}\right)}{2}\right) .
\end{aligned}
$$

The entrepreneur maximizes $U^{\pi}$ with respect to $e_{1}$ and $e_{2}$. Using (B.19), we may write the entrepreneur's first-order conditions in the form

$$
\begin{aligned}
& \frac{\partial U^{\pi}}{\partial e_{1}}=0 \quad \Longrightarrow \quad U_{1}^{\pi}\left(e_{1}, e_{2}, p\right)=0, \\
& \frac{\partial U^{\pi}}{\partial e_{2}}=0 \quad \Longrightarrow \quad U_{2}^{\pi}\left(e_{1}, e_{2}, p\right)=0,
\end{aligned}
$$

where

$$
\begin{gathered}
U_{1}^{\pi}\left(e_{1}, e_{2}, p\right)=p u^{\prime}\left(w^{\pi}-F_{o}+b e_{2}-\frac{c\left(e_{1}^{2}+e_{2}^{2}+2 \alpha e_{1} e_{2}\right)}{2}-P\left(x^{*}-e_{1}\right)\right)\left[P-c\left(e_{1}+\alpha e_{2}\right)\right] \\
-(1-p) u^{\prime}\left(w^{\pi}-F_{o}+b e_{2}-\frac{c\left(e_{1}^{2}+e_{2}^{2}+2 \alpha e_{1} e_{2}\right)}{2}\right) c\left(e_{1}+\alpha e_{2}\right), \\
U_{2}^{\pi}\left(e_{1}, e_{2}, p\right)=p u^{\prime}\left(w^{\pi}-F_{o}+b e_{2}-\frac{c\left(e_{1}^{2}+e_{2}^{2}+2 \alpha e_{1} e_{2}\right)}{2}-P\left(x^{*}-e_{1}\right)\right)\left[b-c\left(e_{2}+\alpha e_{1}\right)\right] \\
+(1-p) u^{\prime}\left(w^{\pi}-F_{o}+b e_{2}-\frac{c\left(e_{1}^{2}+e_{2}^{2}+2 \alpha e_{1} e_{2}\right)}{2}\right)\left[b-c\left(e_{2}+\alpha e_{1}\right)\right] .
\end{gathered}
$$

The system (B.20) and (B.21) implicitly defines $e_{1}$ and $e_{2}$ as functions of $p$. Differentiating the system and solving by Cramer's rule, we find that ${ }^{37}$

$$
\frac{\partial e_{1}}{\partial p}=\frac{-\left(\partial U_{1}^{\pi} / \partial p\right)\left(\partial U_{2}^{\pi} / \partial e_{2}\right)}{\Delta}
$$

\footnotetext{
${ }^{37}$ When deriving (B.24), I use the fact that $\partial U_{2}^{\pi} / \partial p=0$, since (B.21) and (B.23) imply that $b-$ $c\left(e_{2}+\alpha e_{1}\right)=0$.
} 
where $\Delta$ is the determinant

$$
\Delta=\left(\partial U_{1}^{\pi} / \partial e_{1}\right)\left(\partial U_{2}^{\pi} / \partial e_{2}\right)-\left(\partial U_{1}^{\pi} / \partial e_{2}\right)^{2}
$$

The second-order conditions for a maximum require that $\partial U_{2}^{\pi} / \partial e_{2}<0$ and $\Delta>0$, and from (B.22) we get

$$
\begin{gathered}
\frac{\partial U_{1}^{\pi}}{\partial p}=u^{\prime}\left(w^{\pi}-F^{\pi}+b e_{2}-\frac{c\left(e_{1}^{2}+e_{2}^{2}+2 \alpha e_{1} e_{2}\right)}{2}-P\left(x^{*}-e_{1}\right)\right)\left[P-c\left(e_{1}+\alpha e_{2}\right)\right] \\
+u^{\prime}\left(w^{\pi}-F^{\pi}+b e_{2}-\frac{c\left(e_{1}^{2}+e_{2}^{2}+2 \alpha e_{1} e_{2}\right)}{2}\right) c\left(e_{1}+\alpha e_{2}\right) .
\end{gathered}
$$

Since $b>0$, it follows from (B.21) and (B.23) that $c\left(e_{2}+\alpha e_{1}\right)>0$ in the entrepreneur's optimum. From (B.20) and (B.22) we then see that $P-c\left(e_{1}+\alpha e_{2}\right)>0\left(\right.$ since $\left.u^{\prime}>0\right)$. Hence (B.26) implies $\partial U_{1}^{\pi} / \partial p>0$, so from (B.24) we conclude that $\partial e_{1} / \partial p>0$. In other words, as the government principal increases his monitoring intensity, the entrepreneur will provide more services to citizens, as one would expect.

\section{Government expenditure under outsourcing}

Suppose again that the government principal chooses a monitoring intensity which ensures that the service provided equals the benchmark level, i.e., $e_{1}=x^{*}$. From (B.22) and (B.23) we see that the first-order conditions (B.20) and (B.21) then simplify to

$$
\begin{gathered}
p\left[P-c\left(e_{1}+\alpha e_{2}\right)\right]-(1-p) c\left(e_{1}+\alpha e_{2}\right)=0, \\
b-c\left(e_{2}+\alpha e_{1}\right)=0 .
\end{gathered}
$$

Inserting $e_{1}=x^{*}$ in (B.27) and (B.28) and solving for $e_{2}$ and $p$, we get

$$
\begin{gathered}
e_{2}=\frac{b}{c}-\alpha x^{*}, \\
p_{o}^{*}=\frac{c x^{*}\left(1-\alpha^{2}\right)+\alpha b}{P},
\end{gathered}
$$

where $p_{o}^{*}$ denotes the monitoring intensity necessary to induce the service effort $e_{1}=x^{*}{ }^{38}$

Parallel to the case with in-house provision, the principal must secure the entrepreneur an expected payoff $z^{*}$ equal to the outside option. Since the entrepreneur never pays any fine or receives any bonus when $e_{1}=x^{*}$, it follows from (B.16), (B.17), (B.18), (B.29) and (B.30) that the government principal faces the participation constraint

$$
w^{\pi}-F^{\pi}-C=z^{*} \Longrightarrow
$$

\footnotetext{
${ }^{38}$ According to (B.29) we cannot exclude the possibility that the optimal value of $e_{2}$ is negative. Looking at (B.16), we may interpret a scenario with $e_{2}<0$ as a case where the entrepreneur hires labour at the wage rate $b$ to carry out, say, administrative work in the firm so that the entrepreneur can concentrate more effort on servicing the clients.
} 


$$
w^{\pi}=F_{o}+z^{*}+\frac{c\left(x^{*}\right)^{2}}{2}-\frac{b^{2}}{2 c}+\alpha x^{*}\left(b-\frac{\alpha c x^{*}}{2}\right) .
$$

Outsourcing implies that the overhead cost of service production is transferred from the government to the entrepreneur. Instead the government incurs a fixed transaction cost $F^{t}$ representing the administrative cost of implementing a public tender and writing a contract with the private entrepreneur. Hence the government's expenditure under outsourcing $\left(G^{\pi}\right)$ is

$$
\begin{gathered}
G^{\pi}=F^{t}+w^{\pi}+a p_{o}^{*} \Longrightarrow \\
G^{\pi}=F^{t}+F_{o}+z^{*}+\frac{c\left(x^{*}\right)^{2}}{2}-\frac{b^{2}}{2 c}+\alpha x^{*}\left(b-\frac{\alpha c x^{*}}{2}\right)+\frac{a\left[c x^{*}\left(1-\alpha^{2}\right)+\alpha b\right]}{P},
\end{gathered}
$$

where we have used (B.30) and (B.31) to arrive at (B.32).

\section{The potential gain from outsourcing}

By construction, the expenditure levels derived in (B.15) and (B.32) ensure the same benchmark level of public service. Therefore, a straightforward measure of the (positive or negative) gain from outsourcing is the difference between the budgetary cost of inhouse provision $(G)$ and the budgetary cost under outsourcing $\left(G^{\pi}\right)$. Subtracting (B.32) from (B.15), we find after some manipulations that this cost difference is

$$
G-G^{\pi}=\overbrace{F-F_{o}}^{\text {Gain from competition }}+\overbrace{\frac{c e_{2}^{2}}{2}}^{\text {Gain from private ownership }}-\overbrace{\left(F^{t}+\frac{\alpha a c}{P} e_{2}\right)}^{\text {Loss from increased transactions costs }} .
$$

The first term on the right-hand side of (B.33) is the gain arising if the competitive public tender attracts a private service provider who is more efficient than the public inhouse provider in the sense that, even if the private provider does not spend any special effort on bringing down his overhead costs, he nevertheless has a lower fixed cost than the public provider.

The second term on the right-hand side of (B.33) is the cost saving resulting from the private provider's special effort to reduce the overhead costs of service production.

The third term in (B.33) captures the loss from the extra transactions costs implied by outsourcing. It consists of the fixed transaction cost $F^{t}$ plus the additional monitoring $\operatorname{cost} \frac{\alpha a c}{P} e_{2}$ needed to ensure that the private entrepreneur does provide the benchmark service level rather than diverting too much effort from service production to cost-reducing activities.

If competition has the positive effect suggested by economic theory and most empirical evidence, we would expect the first term in (B.33) to be positive. The second term (the incentive effect stemming from private ownership of the service firm) is unambiguously positive. When evaluating the sign of the third term in (B.33), we take $\alpha>0$ (substitutability of work tasks) and $e_{2}$ (positive effort spent on cost reduction) to be the normal scenario. In that case there is an unambiguous loss from higher transactions 
costs when service provision is outsourced. However, we cannot exclude the possibility that $e_{2}<0$ (see the previous footnote). It is also conceivable that the two work tasks are complementary $(\alpha<0)$ in some situations. In such cases outsourcing may actually generate lower transactions cost.

In general, the potential net gain from outsourcing will depend on the relative magnitude of the three effects identified in (B.33), as discussed in section 6.2.

\section{Equivalence of in-house provision and outsourcing under complete con- tracting.}

In the analysis above the difference between in-house provision and outsourcing is that the private entrepreneur is the residual claimant to any cost saving whereas neither the public sector worker nor his immediate principal gain anything from cost-reducing efforts. But suppose it is possible for the principal to write a contract with the public service worker allowing the latter to receive a fraction $\beta$ of any saving of overhead costs resulting from the service worker's cost-reducing effort $e_{2}$. When overhead costs are given by (B.16), the public service worker's income $y$ will then be

$$
\begin{gathered}
y=w+\beta b e_{2}-P\left(x^{*}-e_{1}\right) \quad \text { with probability } p, \\
y=w+\beta b e_{2} \quad \text { with probability } 1-p .
\end{gathered}
$$

By analogy, suppose that under outsourcing the contract with the private service provider stipulates that he must pay a share $\tau$ of any cost saving to the government. The private entrepreneur's income $y^{\pi}$ then becomes

$$
\begin{gathered}
y^{\pi}=w^{\pi}+(1-\tau) b e_{2}-P\left(x^{*}-e_{1}\right) \quad \text { with probability } p \\
y^{\pi}=w^{\pi}+(1-\tau) b e_{2} \quad \text { with probability } 1-p .
\end{gathered}
$$

As a benchmark, suppose further that (i) $\beta=1-\tau$; (ii) the public service worker and the entrepreneur have the same effort cost function (B.17); (iii) the two agents have the same fixed cost function (B.16), and (iv) the fixed transaction cost $F^{t}$ of writing a contract with them is the same. Since the public service worker and the entrepreneur are assumed to have the same preferences and outside options, and since the pay schedules imply exactly the same incentives when $\beta=1-\tau$, it follows that the two agents will then exert the same amounts of effort $e_{1}$ and $e_{2}$.

In other words, when it is possible to write the same type of contract with public sector employees and private entrepreneurs, and if we abstract from the competition effect on overhead costs discussed earlier, there will be no gain from outsourcing, as also pointed out by Knabe and Sørensen (2006, section 5.4). 


\section{REFERENCES}

Andersen, L.B. and M. Jakobsen (2011). Does ownership matter for the provision of professionalized services? Hip operations at publicly and privately owned clinics in Denmark. Public Administration 89: 956-974.

Andersen, L.B. and L.H. Pedersen (2013). Does ownership matter for employee motivation when occupation is controlled for? International Journal of Public Administration 36: 840-856.

Andersson,. F. and H. Jordahl (2011). Outsourcing public services: ownership, commpetition, quality and contracting. IFN Working Paper No. 874, Research Institute of Industrial Economics, Stockholm.

Ballanti, D., R. Dispotico, F. Porcelli and F. Vidoli (2014). A simple four quadrants model to monitor the performance of local governments. Paper presented at the CESifo workshop on "Reforming the Public Sector" at Venice International University, 25-26 July 2014.

Baker, G.P. (1992). Incentive contracts and performance measurement. Journal of Political Economy 100: 598-614.

Barzelay, M. (2000). The New Public Management. University of California Press, Berkeley, CA.

Baumol, W.J. (1967). Macroeconomics of unbalanced growth: The anatomy of urban crisis. American Economic Review 57: 415-426.

Behn, R.D. (1995). The Big Questions of Public Management. Public Administration Review 55: 313-324.

Behn, R.D. (1998). The New Public Management paradigm and the search for democratic accountability. International Public Management Journal 1: 131-164.

Behn, R.D. (2002). The psychological barriers to performance management: or why isn't everyone jumping on the performance-management bandwagon? Public Performance \& Management Review 26: 5-25.

Behn, R.D. (2003). Why Measure Performance? Different Purposes Require Different Measures. Public Administration Review 63: 586-606.

Belfield, C. and H.M. Levin (2005). Vouchers and public policy: when ideology trumps evidence. American Journal of Education 111: 548-567.

Bénabou, R. and J. Tirole (2003). Intrinsic and Extrinsic Motivation. Review of Economic Studies 70: 489-520. 
Besley, T. and A. Case (1995a). Incumbent behaviour: vote seeking, tax setting and yardstick competition. American Economic Review 85: 25-45.

Besley, T. and A. Case (1995b). Does electoral accountability affect economic policy choices? Evidence from gubernatorial term limits. Quarterly Journal of Economics 110: 769-798.

Besley, T. and M. Ghatak (2003). Incentives, choice, and accountability in the provision of public services. Oxford Review of Economic Policy 19: 235-249.

Besley, T. and M. Ghatak (2005). Competition and incentives with motivated agents. American Economic Review 95: 616-636.

Binderkrantz, A.S. and J.G. Christensen (2009). Governing Danish Agencies by Contract: From Negotiated Freedom to the Shadow of Hierarchy. Journal of Public Policy 29: 55 - 78.

Binderkrantz, A.S. and J.G. Christensen (2012). Agency performance and executive pay in government: an empirical test. Journal of Public Administration Research and Theory 22: $31-54$.

Bogetoft, P. (2012). Performance Benchmarking - Measuring and Managing Performance. Springer, New York.

Bordignon, M., F. Cerniglia and F. Revelli (2003). In search of yardstick competition: a spatial analysis of Italian municipality property tax setting. Journal of Urban Economics 54: 199- 217.

Bovenberg, A.L. and P.B. Sørensen (2004). Improving the equity-efficiency trade-off: Mandatory savings accounts for social insurance. International Tax and Public Finance 11: 507-529.

Bovenberg, A.L., M.I. Hansen and P.B. Sørensen (2012). Efficient redistribution of lifetime income through welfare accounts. Fiscal Studies 33: 1-37.

Boyne, G.A. (2002). Public and private management: what's the difference? Journal of Management Studies 39: 97-122.

Bunse, S. and V. Fritz. Making public sector reforms work - Political and economic contexts, incentives, and strategies. The World Bank, Policy Research Working Paper 6174, August 2012.

Buurman, M., J. Delfgaauw, R. Dur and S. Van den Bossche (2012). Public sector employees: risk averse and altruistic? Journal of Economic Behavior \& Organization 83: 279-291.

Cherchye, L., W. Moesen, N. Rogge, T. Van Puyenbroeck (2006). An Introduction To Benefit of the Doubt Indicators. Social Indicators Research 82: 111-45.

Christensen, T. and P. Lægreid (2007). The Whole-of-Government approach to public sector reform. Public Administration Review, November/December 2007: 1059-1066. 
Danish Productivity Commission (2013). Overenskomster, Arbejdstid og Løndannelse i den Offentlige Sektor (Collective Bargaining Agreements, Work Hours and Wage Formation in the Public Sector). Background report, Copenhagen, September 2013.

Danish Productivity Commission (2014a). Offentlig-Privat Samarbejde (Public-Private Cooperation). Analyserapport 6, Copenhagen, February 2014 (www.produktivitetskommissionen.dk).

Danish Productivity Commission (2014b). Det Handler om Velstand og Velfærd (Prosperity and Welfare). Final report, Copenhagen, March 2014 (www.produktivitetskommissionen.dk).

Delfgaauw, J. and R. Dur (2008). Incentives and workers' motivation in the public sector. Economic Journal 118: 171-191.

Dixit, A. (2002). Incentives and organizations in the public sector: An interpretative review. Journal of Human Resources 37: 696-727.

DREAM Modelling Group (2014). Produktiviteten i den offentlige sektor (Productivity in the public sector). Working Paper, March 2014 (www.dreammodel.dk).

Dunleavy, P., H. Margetts, S. Bastow and J. Tinkler (2005). New Public Management is dead Long live Digital-Era Governance. Journal of Public Administration Research and Theory 16: 467-494.

Ekelund, R.B. and R.F. Hébert (1997). A History of Economic Theory and Method. Fourth Edition. New York: McGraw-Hill.

Epple, D. and R.E. Romano (1998). Competition between private and public schools, vouchers, and peer-group effects. American Economic Review 88: 33-62.

Francois, P. (2000). 'Public service motivation' as an argument for government provision. Journal of Public Economics 78: 275-299.

Frey, B. (1997). A constitution for knaves crowds out public virtues. Economic Journal 107: 1043-1053.

Frey, B. and R. Jegen (2001). Motivation crowding theory. Journal of Economic Surveys 15: 589-611.

Gneezy, U., S. Meier and P. Rey-Biel (2011). When and why incentives (don't) work to modify behavior. Journal of Economic Perspectives 25: 191-209.

Gregg, P., P.A. Grout, A. Ratcliffe, S. Smith and F. Windmeijer (2011). How important is prosocial behaviour in the delivery of public services? Journal of Public Economics 95: 758-766. 
Gregory, R.G. and J. Borland (1999). Recent developments in public sector labor markets. Chapter 53 in O. Ashenfelter and D. Card (eds.), Handbook of Labor Economics, Volume 3, Elsevier Science B.V.

Greve, C. (2013). Ideas in public management reform for the 2010s. Digitalization, value creation and involvement. Public Organization Review, November 2013, DOI 10.1007/s11115013-0253-8.

Gruening, G. (2001). Origin and theoretical basis of New Public Management. International Public Management Journal 4: 1-25.

Hart, O., A. Shleifer and R. Vishny (1997). The proper scope of government: theory and an application to prisons. Quarterly Journal of Economics 112: 1127-1161.

Heyndels, B. and J. Vuchelen (1998). Tax mimicking among Belgian municipalities. National Tax Journal 51: 89- 101.

Hodge, G.A. and C. Greve (2009). PPPs: the passage of time permits a sober reflection. Economic Affairs 29: 33-39.

Hodge, G.A., C. Greve and A.E. Boardman (eds.) (2010). International Handbook on Public Private Partnership. UK: Edward Elgar Publishing.

Holmström, B. (1979). Moral hazard and observability. Bell Journal of Economics 10: 74-92.

Holmström, B. (1982). Moral hazard in teams. Bell Journal of Economics 13: 324-340.

Holmström, B. and P. Milgrom (1991). Multitask principal-agent analysis: incentive contracts, asset ownership, and job design. Journal of Law, Economics and Organization 7 (special issue): $24-52$.

Hood, C. (1989). Public Administration and public policy: intellectual challenges for the 1990s. Australian Journal of Public Administration 48: 346-358.

Hood, C., O. James and C. Scott (2000). Regulation of government: has it increased, is it increasing, should it be diminished? Public Administration 78: 283-304.

Hood, C. and G. Peters (2004). The middle-aging of New Public Management: into the age of paradox? Journal of Public Administration Research and Theory 14: 267-282.

Høj, J., V. Galasso, G. Nicoletti and T-T. Dang (2006). The political economy of structural reform: Empirical Evidence from OECD countries. OECD Economics Department Working Papers, No. 501, OECD Publishing. 
Jakobsen, M.L.F. and R.J. Sørensen (2012). Er offentligt ansatte (blevet) som de private? En analyse af arbejdsmotivation i den offentlige og private sektor over tid. Politica 44: 26-46.

Jakobsen, M.L.F. and P.B. Mortensen (2014). Regelstaten. Væksten i danske love og bekendtgørelser 1989-2011. Copenhagen, Djoef Publishing.

Jensen, P.H. and R.E. Stonecash (2005). Incentives and the efficiency of public sector outsourcing contracts. Journal of Economic Surveys 19: 767-787.

Kaufman, H. (1977). Red Tape: Its Origins, Uses, and Abuses. Washington, DC: Brookings Institution.

Knabe, A. and P.B. Sørensen (2006). Outsourcing of public service provision: When is it more efficient? Finnish Economic Papers 19: 3-15.

Kreps, D. M. (1997). Intrinsic motivation and extrinsic incentives. American Economic Review 87: 359-364.

Ladd, H.F. (2002). School vouchers: a critical view. Journal of Economic Perspectives 16: 3-24.

Lapsley, I. (2009). New Public Management: the cruellest invention of the human spirit? ABACUS 45: 1-21.

Lazear, E.P. (1996). Performance pay and productivity. National Bureau of Economic Research Working Paper 5672, July 1996.

Light, P. (1993). Monitoring Government. Washington, D.C.: The Brookings Institution.

Matheson, A. and H.-S. Kwon (2003). Public sector modernisation: a new agenda. OECD Journal on Budgeting 3: 7-23.

Megginson, W.L. and J.M. Netter (2001). From state to market: a survey of empirical studies on privatization. Journal of Economic Literature 39: 321-389.

Moynihan, D.P. and P.W. Ingraham (2003). Look for the silver lining: when performancebased accountability systems work. Journal of Public Administration Research and Theory 13: 469-490.

National Performance Review (1993). From Red Tape to Results: Creating a Government that Works Better and Costs Less. Washington, DC: U.S. Government Printing Office.

Nielsen, P.A. (2013). Public management, managerial authority, and public service performance. Forthcoming in Journal of Public Administration Research and Theory.

OECD (2013). Government at a Glance 2013. OECD Publishing. 
OECD and European Commission (2008). Handbook on Constructing Composite Indicators Methodology and User Guide. OECD.

Petersen, O.H. (2013). Offentlige-private partnerskaber (OPP). Notat om danske og internationale erfaringer med OPP. KORA, Det Nationale Institut for Kommuners og Regioners Analyse og Forskning. København, april 2013.

Petersen, O.H. and U. Hjelmar (2014). Marketization of welfare services in Scandinavia: a review of Swedish and Danish experiences. Scandinavian Journal of Public Administration 17: $3-20$.

Pollitt, C., S. van Thiel and V. Homburg (2007). New Public Management in Europe. Management Online Review, October 2007 (www.moreexpertise.com).

Prendergast, C. (2011). What have we learnt about pay for performance? The Economic and Social Review 42: 113-134.

Revelli, F. (2006). Performance rating and yardstick competition in social service provision. Journal of Public Economics 90: 458-474.

Revelli, F. and P. Tovmo (2007). Revealed yardstick competition: Local government efficiency patterns in Norway. Journal of Urban Economics 62: 121-134.

Rainey, H.G. and B. Bozeman (2000). Comparing public and private organizations: Empirical research and the power of the a priori. Journal of Public Administration Research and Theory 10: $447-469$.

Sandmo, A. (2014). The market in economics: behavioural assumptions and value judgments. Paper presented at the conference on Markets, Ethics and Religion held at the Danish Academy of Science and Letters, Copenhagen 6-7 February, 2014.

Savoie, D.J. (1995). What is wrong with the new public management? Canadian Public Administration/Administration Publique Du Canada 38: 112-121.

Schaltegger, C. and D. Kuttel (2002). Exit, voice, and mimicking behaviour: evidence from Swiss cantons. Public Choice 113:

$1-23$.

Silberberg, E. and W. Suen (2001). The Structure of Economics - A Mathematical Analysis. Third Edition, McGraw-Hill.

Social Services Inspectorate (2002). Performance Ratings for Social Services in England. Department of Health, London. 
Stamp, J. (1927). The statistical verification of social and economic theory. The Sidney Ball Lecture, November 5, 1926. Barnett House Papers, No. 10, London: Oxford University Press.

Tirole, J. (1994). The internal organization of government. Oxford Economic Papers 46: 1-29.

Tobin, J. (1970). On limiting the domain of inequality. Journal of Law and Economics 13: 263-277.

Van Thiel, S. and F.L. Leeuw (2002). The performance paradox in the public sector. Public Performance and Management Review 25: 267-281.

Valkama, P. and S.J. Bailey (2001). Vouchers as an alternative public sector funding system. Public Policy and Administration 16: 32-58.

Visser, J. (2006). Union membership in 24 countries. Monthly Labor Review, January 2006: $38-49$.

Weber, M. (1947). The Theory of Social and Economic Organization (translation by A.M. Henderson and T. Parsons). Glencoe, IL: The Free Press.

Wilson, W. (1887). The study of administration. Political Science Quarterly 2. Reprinted on pp. 1l-24 in J. M. Shafritz and A. C. Hyde (eds.), Classics of Public Administration, 3rd ed., Pacific Grove, CA: Brooks/Cole.

Wittrup, J., K. Houlberg, A.L.T. Jordan and P. Bogetoft (2013). Kommunale serviceniveauer og produktivitet. KORA, Det Nationale Institut for Kommuners og Regioners Analyse og Forskning. Copenhagen (www.produktivitetskommissionen.dk).

Worthington, A.C. and B.E. Dollery (2000). An empirical survey of frontier efficiency measurement techniques in local government. Local Government Studies 26: 23-52. 